\title{
The epidemic emergence of HIV: what novel enabling factors were involved?
}

\author{
João Dinis Sousa*,1,2, Viktor Müller ${ }^{3,4}$ \& Anne-Mieke Vandamme ${ }^{1,2}$ \\ ${ }^{1}$ Department of Microbiology \& Immunology, Rega Institute for Medical Research, Clinical \& Epidemiological Virology, KU Leuven - \\ University of Leuven, B-3000, Leuven, Belgium \\ ${ }^{2}$ Center for Global Health \& Tropical Medicine, Unidade de Microbiologia Médica, Instituto de Higiene e Medicina Tropical, \\ Universidade Nova de Lisboa, Lisbon, Portugal \\ ${ }^{3}$ Institute of Biology, Eötvös Loránd University, Budapest, Hungary \\ ${ }^{4}$ Evolutionary Systems Research Group, MTA Centre for Ecological Research, Tihany, Hungary \\ * Author for correspondence: joao.sousa@kuleuven.be
}

Humans acquired retroviruses from simians, mainly through bushmeat handling. All epidemically successful HIV groups started to spread in early 20th century, contrasting with the antiquity of T-cell lymphotropic viruses, implying that novel enabling factors were involved in HIV emergence. Here we review the Parenteral Serial Transmission and the Enhanced Heterosexual Transmission hypotheses for the adaptation and early spread of HIV. Epidemic start roughly coincides in time with peak genital ulcer disease in cities, suggesting a major role for sexual transmission. Only ill-adapted and rare HIV groups emerged after approximately 1950, when injections and transfusions attained their maximal levels, suggesting that if parenteral serial transmission was necessary for HIV adaptation, it had to be complemented by sexual transmission for HIV to reach epidemic potential.

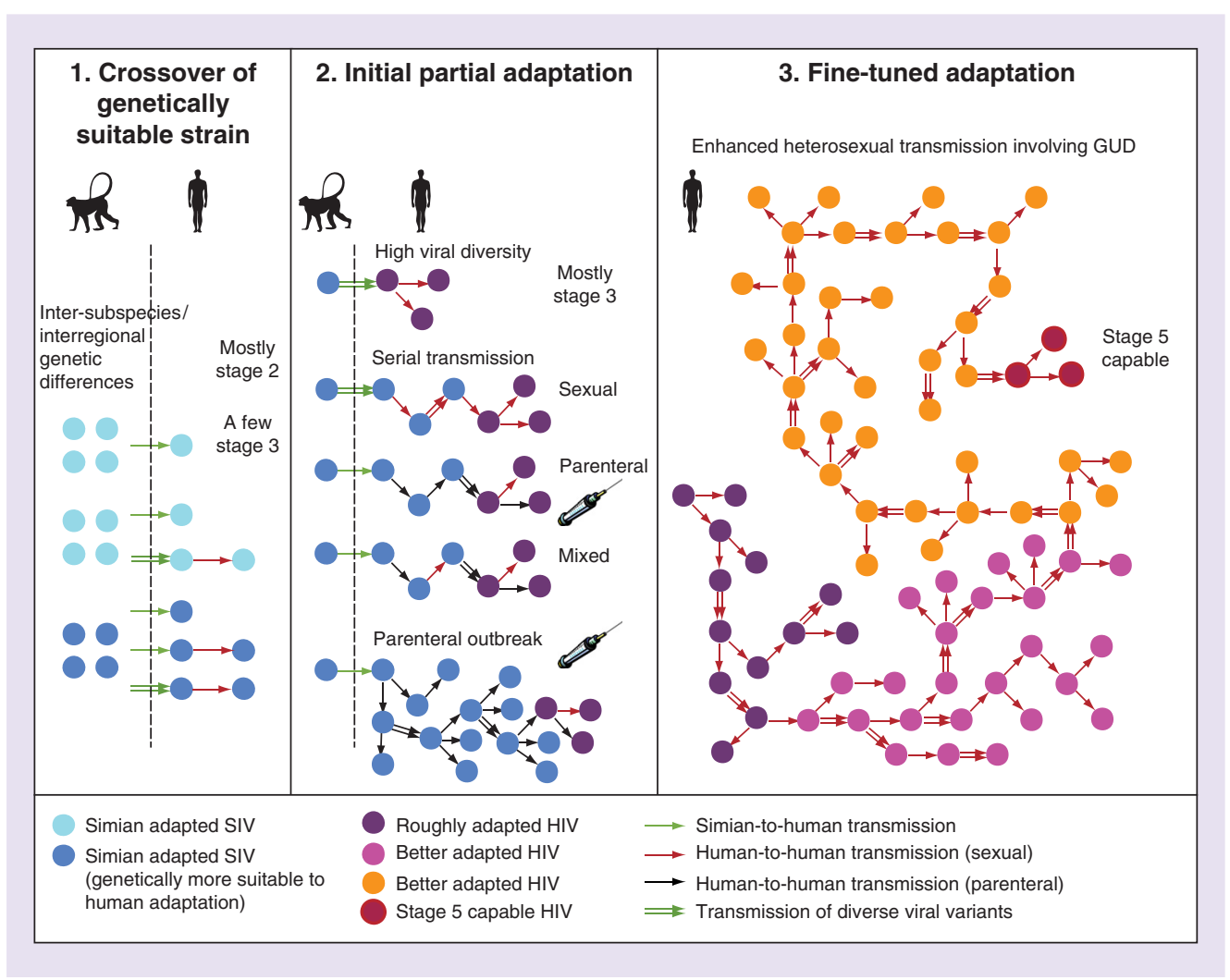

First draft submitted: 31 March 2017; Accepted for publication: 26 July 2017; Published online: 20 October 2017 
Keywords: Central Africa $\bullet$ genital ulcer disease $\bullet$ HIV $\bullet$ male circumcision $\bullet$ origin of HIV $\bullet$ unsterile injections - West Africa

Both human immunodeficiency virus types (HIV-1 and HIV-2) have been acquired by humans from nonhuman primates infected with simian immunodeficiency virus (SIV). HIV-1 comprises four known groups, each demonstrably derived from an independent simian-to-human transmission [1]. The pandemic group M (HIV-1-M), and the rare group N (HIV-1-N) originated from SIV infecting central chimpanzees (Pan troglodytes troglodytes; SIVcpz) living in southeast and south-central Cameroon, respectively [1-3]. HIV-1 group O (HIV-1-O, which infects $<20,000$ people in Central Africa) and the rare group P (HIV-1-P) originated from SIVgor, endemic in western lowland gorillas (Gorilla gorilla gorilla) [4,5]. HIV-2 is divided into nine known groups (A-I), all independent crossovers from SIVsmm, infecting West African sooty mangabeys (Cercocebus atys atys) [6-9]. Of these, only groups A and B have spread widely, probably infecting together more than one million people [10]; HIV-2 groups D and F were found in two individuals each $[6,8,9]$; the remaining HIV-2 groups (C, E, G-I) were identified in just one person each [6,7], and might therefore not deserve the classification of a group.

SIV infection is reportedly present in 45 of the 73 known species of African primates, and SIV-carrying primate species reach most areas of sub-Saharan Africa [11]. However, it is not clear why only SIVcpz, SIVgor and SIVsmm generated epidemics in humans. For a successful cross-species transmission, SIV needs to be able to use the appropriate receptors and co-receptors on the cells of the new host, and to adapt to counteract host-specific restriction factors, such as APOBEC3G, TRIM5 $\alpha$, or tetherin. Variation might exist among SIVs in their degree of preadaptation to any of these human biological restrictions $[1,3,12]$, but data to support this are currently lacking for most SIV variants.

It is generally accepted that humans acquired these viruses from simians through bushmeat handling $[1,7]$. While the phylogenetic structure of HIV groups and their relation to SIVs are now well established, the processes that led to their epidemic emergence are still debated. In the absence of solid evidence of causation, this debate is largely based on correlation analyses. Here we review the state of this debate, including our own contribution to it, and attempt to outline the likely future evolution in this field. We will focus on the three SIVs that are linked to HIV epidemics.

\section{Staging the transformation of SIV to epidemic HIV \& evidence of concomitant adaptation}

According to Wolfe et al. (2007) [13], an animal pathogen can be transformed into a specialized pathogen of humans through five evolutionary stages, the more advanced of which require adaptation. In Stage 1, the pathogen is still present in animals only. In Stage 2, it is able to infect humans, but there is no human-to-human transmission (e.g., rabies). In Stage 3, limited transmission between humans occurs, but it is not sustained, the outbreaks die out (e.g., Ebola). In Stage 4, transmission between humans is important, but many new imports from animals ('sylvatic transmission') are constantly occurring (e.g., dengue). In Stage 5, the pathogen is exclusively human and the epidemic is self-sustained (e.g., epidemic HIV, Plasmodium falciparum) [13].

Two large-scale studies found $8-17 \%$ SIV seroreactivity in modern HIV negative Central Africans exposed to bushmeat, its frequency correlated with exposure. No viruses could be isolated or sequenced [14,15]. Thus, human SIV infections are frequent, but mostly unproductive and not transmitted further, which classifies them mostly as Stage 2 infections. The rare HIV-2 groups found in just one patient each (C, E, G, H, I) may also be examples of Stage 2; there is currently no evidence for higher stages. The rare HIV groups that have demonstrably spread among humans (HIV-1-N, HIV-1-P, HIV-2-D and HIV-2-F) may represent short-lived outbreaks (Stage 3), with some potential to transition to higher stages $[1,16-19]$.

The rare forms of HIV-2, one of the two known HIV-1-P isolates, and also the epidemic HIV-2-B, have the amino acid methionine in the Gag30 position, like SIVcpz, SIVgor and SIV smm. In contrast, HIV-1-M, HIV-1-O, HIV-1-N and HIV-2-A have all evolved an arginine at this position, and careful experiments demonstrated that this convergent change is an adaptation to the human host $[1,16]$. The four epidemic groups of HIV (HIV-1-M, HIV-1-O, HIV-2-A, HIV-2-B) each derive from a single simian-to-human transfer and now infect between tens of thousands to millions of people, so they have all clearly undergone the transitions to Stage 5. Several studies have demonstrated various additional adaptations as compared with the rare groups: adaptations to human host restriction factors, receptors and human leucocyte antigens (HLA). HIV-1-M, HIV-1-O and HIV-2 have all evolved the capacity to antagonize human tetherin, controlled by genomic sites in Vpu, Nef and Env, respectively, while their ancestors (SIVcpz, SIVgor and SIVsmm) all use Nef to combat simian tetherin (HIV-1-O evolved this 
function through a site in Nef different from the site used by SIVgor) $[1,17,18]$. There are other HIV adaptations, such as downregulation of human CD4, HLA-A, HLA-B and HLA-C [1,19].

\section{The timing of the HIV groups \& the evidence for novel factors enabling epidemic emergence}

The timings of human T-cell lymphotropic viruses (HTLV), the first group of human retroviruses discovered, contrast with those of HIVs. The estimated time of the most recent common ancestor (tMRCA) of the different HTLV type 1 (HTLV-1) subtypes span between approximately 5000 and 50,000 years ago [20,21], while HTLV-2 has crossed into humans between 60,000 and 400,000 years ago [20-22]. The slave trade of the centuries preceding the 20th, exported some HTLV-1 subtypes [22] to the Americas, confirming their ancient origin. Simian foamy virus, the only other simian retrovirus infecting humans through bushmeat handling, infects many Central Africans, but there is no evidence of ongoing transmission between humans [23] (i.e., simian foamy virus is stuck in Stage 2).

In contrast to HTLV, all known HIV groups emerged recently and the epidemic groups did so almost simultaneously in the first half of the 20th century. This was shown by phylogenetic analyses that were used to estimate the tMRCA of the main epidemic strains. For HIV-1-M, estimates of tMRCA fall in the period 1908-1930 [24-27]; the most recent analyses calculated 1908 (1884-1924) [26] and 1920 (1909-1930) [27]. A similar time-frame was estimated for HIV-1-O at 1920 (1890-1940) [28], and the tMRCAs of HIV-2 groups A and B were estimated at 1938 (1928-1947) [29] and 1945 (1931-1959) [30], respectively. The rare HIV groups seem to be younger. For HIV-1-N, a tMRCA of 1963 (1948-1977) was estimated [31]. No tMRCA calculation was performed for HIV-1-P, since only two strains are known, but their split is approximately as deep as the HIV-1-N MRCA [4]. Similarly, the split between the two known lineages of HIV-2-F appears to be more recent than both the tMRCAs of HIV-2-A and HIV-2-B [9]. There is currently no evidence supporting the presence of HIV outside Africa prior to the 1960s. All HIV viruses sequenced from African-Americans to date belong to one of the known HIV groups, the origin of which appears to be after late 19th century, and their spread out of Africa has been dated phylogenetically to after the 1960s.

Several lines of evidence suggest that opportunities for simian-human cross-species transmission of SIV have long been present in Africa. First, an analysis of SIV sequences of monkeys inhabiting the Bioko island, which became isolated from mainland Africa 10,000-12,000 years ago, permitted to calibrate the entire SIV phylogenetic tree, suggesting an estimate for the age of this virus group of at least 77,000 (33,000-133,000) years [32], consistent with an ancient presence of SIV on the African continent. Second, the large-scale serological studies of Central Africans exposed to bushmeat [14,15], suggest SIV infections are common and related to bushmeat handling. Therefore, the epidemic emergence of HIV (i.e., the transition of HIV to Stage 5) was most likely helped/enabled by novel factors becoming effective after late 19 th century. This timing consideration led to several hypotheses of enabling factors, including urbanization, sexually transmitted diseases (STD), unsafe injections, and transfusions [33-43].

\section{Potential enabling factors}

The origin of the HIV epidemics and the HIV-1 group M pandemic raises at least three different 'how' questions: how did the original jump of SIV to humans take place?; how did adventitious SIVs turn into HIVs acquiring epidemic or pandemic potential (i.e., Stage 5 potential)?; and, how are the current epidemics and pandemic progressing (which factors fuel spread)? With regard to the first question, the original interspecies jump was a result of bushmeat hunting, butchering or handling, as is widely recognized [1,2,35-43], and we argued above that this had been happening for millennia without giving rise to HIV. With regard to the third question, the current epidemics of HIV in African populations are mostly fueled by heterosexual transmission [44,45]. So, the first and third questions are not contentious. The second question is more difficult to investigate empirically. It raises also the question which process permitted adaptation to evolve.

Emergence and early spread of HIV may have been enabled by several factors. Some of them may have favored more interspecies transmissions, some may have favored incipient adaptation, and some may have helped humanto-human transmission even of ill-adapted strains. None of these enabling factors are mutually exclusive, some of them probably acted in concert and some of them had long been present in tropical Africa. However, to explain the observed phylogenetic pattern, a particular combination of such factors or some specific factors must have been novel, not present before the late 19th century, and some of the novel factors may have been indispensable for the transition.

Already in prehistoric times, human bushmeat hunting of primates likely caused numerous Stage 2 (dead-end) human infections with SIV, and possibly some short-lived Stage 3 outbreaks. Organized colonialism started in inner 
Central and West Africa around 1885. It triggered several changes potentially relevant for HIV emergence: possible increase in primate hunting, urbanization and related social changes [26,46], medical injections, vaccinations, and transfusions [34-39], and spread of sexually transmitted infections (STI) and related diseases (STD) [40,41]. Some of these factors may have increased human exposure to SIV, while others may have increased either parenteral or sexual transmission potential - which may have been important for adaptation and early spread of a still ill-adapted zoonotic virus. These processes may have generated more common Stage 3 outbreaks.

Adaptation to host restriction factors may have been facilitated by biological processes that are not novel, such as the high viremia during acute infection [35], a high transmitted viral diversity upon cross-species transfer [47-49], or synergistic interactions with other pathogens [50]. Even within a single SIV species some strains may be better pre-adapted to sustain infection in humans than others, as was demonstrated for SIVcpz [3]. Host susceptibility factors may also have played a role: lack of male circumcision [43], cytokine profile, or HLA haplotype [51].

Among the synergistic interactions, several pathogens are known to increase HIV viral load [52]. In addition, STD-causing pathogens faciliate HIV transmission by increasing inflammation and HIV genital viral load, and additional mechanisms [40,53,54].

Here we concisely review these factors and their possible contribution. We pay special attention to the factors that could have enhanced either sexual or parenteral transmission for the following reasons. First, they might have helped adaptation [35,36]. Second, they either started or greatly intensified after organized colonialism began (as we will discuss), thus meeting the criterion of novelty. And third, most of the published hypotheses of HIV origins has focused on them.

\section{Viral diversity \& adaptation to a new host species}

Pathogenic and adapted SIVmac, SIVstm and SIVmne emerged in captive Asian macaques in the 1970s, and resulted from several accidental cross-species transfers of SIVsmm from sooty mangabeys in captivity. A phylogenetic analysis suggests that highly invasive kuru experiments (likely to transmit high viral diversity) caused most of these crossspecies transfers and allowed further serial passage in the new host species [55]. Similarly, in experimental transfer of SIVsmm to rhesus macaques, the initial transmitted diversity greatly contributed to adaptation to the new host [47]. Thus, several experiments suggest that upon cross-species transfer, viral diversity matters to facilitate adaptation.

After more than 100 chimpanzees were experimentally infected with HIV-1, only the strain $\mathrm{HIV}-1_{\mathrm{NC}}$ readapted sufficiently to the former host and causes AIDS. HIV-1 $1_{\mathrm{NC}}$, a recombinant between HIV-1 $1_{\mathrm{LAV} 1 \mathrm{~b}}$ and HIV-1 $1_{\mathrm{SF} 2}$, evolved in one of the few animals that were superinfected with multiple HIV-1 strains. After evolving in one host, HIV-1 $1_{\mathrm{NC}}$ promptly caused CD4 T-cell decline when transmitted to other chimpanzees [48,49]. Thus, superinfection and recombination may be important for adaptation after a cross-species transfer.

Drawing a parallel with HIV origins, these studies could suggest that, among SIV-infected humans, a minority may have received larger blood inoculums (e.g., a deep wound), or may have been multiply infected in a short period (e.g., after butchering two or more primates), thereby acquiring a higher diversity of SIV, potentiating partial adaptation. This might have been a template for Stage 3 human HIV infections even in ancient times. However, such events have been occurring for millennia, and Stage 5 HIV did not emerge. Thus, further adaptation than that potentiated by any of these processes was probably needed to generate several long-lasting HIV epidemic groups nearly simultaneously in the 20th century.

\section{Large population agglomerations \& firearms were not novel factors}

Firearms were smuggled in great numbers to southeast Cameroon and nearby areas in early 20th century, peaking in the period 1900-1907 [41,56]. They facilitate ape hunting, and there are reports that the latter was common in the region by that time [41]. However, firearm exports from Europe to Africa had been massive for centuries, including to the inner Congo basin [57,58], so they were not a novel factor in early 20th century.

Well before colonialism, several towns/agglomerations existed in forested Central Africa with populations up to approximately 10,000, comparable to the colonial cities of the period 1910-1925 [58]. Thus, urbanization, in the strict sense of larger agglomerations, was not a novel factor. However, colonial urbanization may have been favorable to HIV emergence because of the associated profound societal changes [38,40].

\section{The serial transmission hypothesis of adaptation to a new host species}

HIV adaptation to humans was necessary for epidemic emergence. Nonadapted adventitious SIV is unlikely to sustain detectable viral load after acute infection $[14,15]$ and potential human-to-human transmission is therefore 
(A)

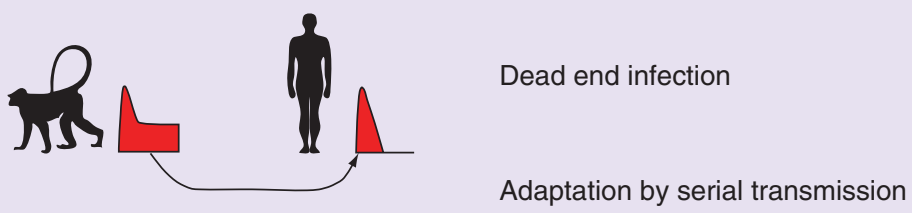

(B)

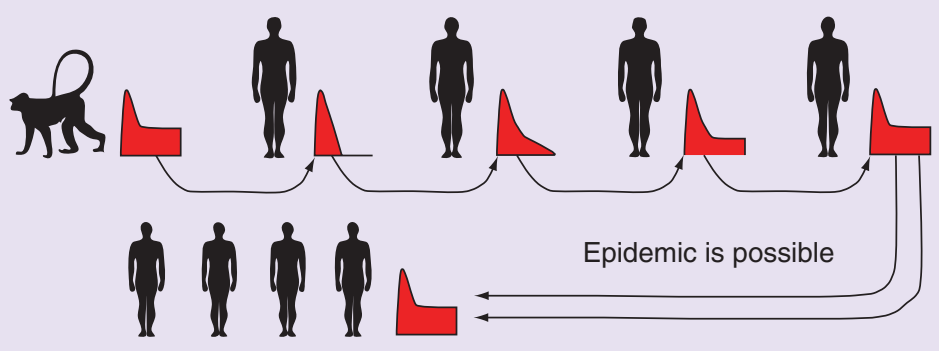

Figure 1. The process of simian immunodeficiency virus adaptation by serial transmission. In a typical cross-species transmission of SIV the virus is suppressed after acute infection initially (A); with serial transmission through sequential acute-stage infections, the virus gradually adapts to the new host and acquires the ability to sustain substantial viral load past acute infection (B). The time course of the viral load in the individual infections is shown in red (X-axis is time since infection, Y-axis is viral load).

SIV: Simian immunodeficiency virus.

For color figures please see www.futuremedicine.com/doi/full/10.2217/fvl-2017-0042

restricted to acute infection. Marx et al. [35] proposed that SIV might have adapted to humans, becoming HIV, by accumulation of favorable mutations during a few serial transmissions among humans, transmitted in the acute stage of the infection. The concept of adaptation of a virus to a new host species by serial transmission is supported by experimental serial passage of SIV among macaques [35,55] and of H5N1 among ferrets [59]. The process is illustrated in Figure 1.

Marx et al. proposed that the arrival of medical injections to Africa following European colonization (with significant inland penetration only after the Berlin Conference in 1885) provided the means for serial transmission of SIV to occur, since sterilization of equipment was often absent [35]. In this parenteral serial transmission hypothesis, unsterile injections only provide the initial adaptive event; it does not imply that subsequent transmission is mainly parenteral.

Injections were already common in early 20th century Central and West Africa [34,36-38,41], particularly to treat syphilis, yaws and trypanosomiasis, and to vaccinate against smallpox, and they could have enabled serial transmission. Moreover, many were intravenous, posing a higher risk of SIV/HIV transmission [44,45] than the mostly intramuscular injections performed after 1950 .

Gisselquist emphasized that campaigns against trypanosomiasis in Cameroon, in which many rural patients were treated together by mobile teams, could have caused adaptation of HIV-1-M and HIV-1-O [36]. Our own review of archival and colonial medical data for Cameroon show that trypanosomiasis treatments peaked in 1924-1928 (thus roughly coinciding with the tMRCAs) and then declined, becoming negligible in the 1950s [41].

Schneider and Drucker suggested a possible role of blood transfusions in the origin of HIV [39]. The probability of HIV-1 transmission per transfusion is $>90 \%$. However, transfusion services or programs seem to have been established in the Belgian Congo (now Democratic Republic of Congo) and Senegal in the 1940s, and reached many more African countries only in the next decade. There are only isolated reports of transfusions from the 1920 s [39]. However, in a few desperate trypanosomiasis cases, blood taken from convalescent patients was sometimes injected [38]. 


\section{Other parenteral hypotheses \& evaluation of related risk factors} The massive parenteral transmission hypothesis

Pépin and Labbé and Pépin proposed that unsafe injections used mainly against syphilis, yaws, and trypanosomiasis might have massively transmitted SIV/HIV in rural areas, generating thousands of infections, with sexual transmission taking over only later on [37,38]. We call this the massive parenteral transmission hypothesis.

HIV epidemic expansion by the parenteral route has only been reported in groups of intravenous drug users (IVDU), and in some hospital outbreaks, characterized by extremely high levels of needle sharing/reuse. Western IVDUs inject themselves 300-1800 times a year and rapid HIV-1 spread happened more commonly in the 1980s, when the number of unsafe needle shares per IVDU per year was 60-245 [41]. After needle exchange programs and other harm reduction interventions reduced the sharing frequency to $<30$ per IVDU per year, HIV-1 declined or became stagnant in this risk group (i.e., with a basic reproductive number, $\mathrm{R}_{0}<1 ; \mathrm{R}_{0}$ measures the number of new infections caused by a single infected during his/her infectious period in a fully susceptible population; an epidemic can only be started if $\mathrm{R}_{0}>1$ ). In contrast, the parenterally more transmissible hepatitis $\mathrm{C}$ virus (HCV) has remained at high prevalence (for details, see our review [41]). Similarly, in the rare documented HIV-1 hospital outbreaks, needles were reused in patients with annual frequencies estimated at 40-200 per patient, with riskier procedures also present $[41,44,60]$.

Colonial medical articles reveal a far lower injection load in Central African rural populations in early 20th century. Each person was inoculated against smallpox once each 5-8 years. In 1922-1931 Cameroon, the average number of injections per patient per year in the treatment of yaws and syphilis was in the range 1.0-1.9 (including arsenicals, bismuthics and mercurials). In rural clinics, syphilis treatments could involve a few more, but normally $<4$. Only in major cities, some specialized STD clinics administered $>15$ injections per syphilis patient, starting in approximately 1930 [41,61]. New trypanosomiasis patients in the period 1925-1935 would receive 6-12 injections in the first year, and normally no more than 15-24 spread over 2 or more years $[41,62]$. Moreover, only about half of these injections were intravenously administered (e.g., tryparsamide, rather than the intramuscular atoxyl) [41,62].

We conclude that the early 20th century Central African rural injection campaigns had an overall injection intensity one to two orders of magnitude lower than the intensity of needle sharing required for IVDU and hospital outbreaks where HIV-1 demonstrably had $\mathrm{R}_{0}>1$ [41]. Thus, they may have spread HCV extensively [63] (as happened with antischistosomiasis campaigns in Egypt, which had similar injection intensity [64]), but this has not been demonstrated for HIV-1.

Finally, under the massive parenteral transmission hypothesis, we would expect more successful epidemic HIV groups to have arisen in the antibiotic era (post-1950), when injections (many unsterile) became more common, but the opposite is observed. It is remarkable that even with unsafe injections peaking across Africa in the period 1960-2000 [35,65], coinciding with the epidemic spread of the virus across the continent, $<3 \%$ of HIV-1 infections in Africa have been estimated to have been acquired by unsafe injections [44,45]. This suggests that unsafe injections alone are unlikely to boost HIV-1 $\mathrm{R}_{0}$ above 1 . For all these reasons, we consider this hypothesis unlikely.

\section{The parenteral outbreak hypothesis}

However, although overall injection intensity was low in early 20th century, it could have been substantially higher at selected locations and during short periods (i.e., concentrated in time and space). Thus, we could devise a parenteral outbreak hypothesis by which, in a health facility with unusually high parenteral risks (as in modern hospital outbreaks $[41,44,60]$ ) ill-adapted HIV suddenly spread to some dozens of people. By infecting multiple hosts, the virus would have higher chances of acquiring favorable mutations and hence adapting, later being transmitted mostly by sexual contact.

For example, in the Croix Rouge STD clinic of Leopoldville (established in 1929), syphilis patients received 15-24 injections per year in 1933-1940 [41,61]. In the same city in the 1920s, very sick trypanosomiasis patients were segregated in a lazaret and received dozens of injections per year [66].

\section{Patterns of needle \& syringe sterilization}

Autoclaves were already used in the Brazzaville hospital for Africans as early as 1908 [67], and sources suggest their use in the main Gabonese medical centres as well [38]. In the Belgian Congo, a source mentions 'disinfection pavillions', equipped with 'disinfection machines' (which could be autoclaves or dry heat devices) in 1929, in the hospitals for Africans of Leopoldville (now Kinshasa) and Stanleyville [68] - suggesting that the same was probably true for the other main cities. The Leopoldville Laboratory, to which the trypanosomiasis lazaret was attached, had 
a sterilization room with autoclaves by 1922 [66]. These reports suggest that most hospitals of the main colonial cities had these devices in early 20th century. In minor clinics of the countryside, sterilization of syringes, needles and lancets was done by boiling [41,69,70].

However, as reviewed by Pépin [38], full sterilization by boiling or autoclave was mostly performed on an endof-day basis; when there was a long queue of patients to inject in a single day, cleaning of equipment between one injection and the next had to be done by fast procedures: rinsing the needles and syringes with water, phenylated water, alcohol or ether, passing the needles by a flame or plunging them in burning alcohol (reviewed in $[38,41]$ ). These fast procedures would not sterilize fully and, in addition, often they were missed altogether, particularly when practiced by inexperienced and/or unscrupulous healthcare workers in rural campaigns [38,70]. Even in Leopoldville, many injections were probably unsterile, particularly in the Croix Rouge clinic [38], and they may therefore have transmitted HIV-1. Both clinical data and phylogenetic analyses suggest that unsafe injections amplified hepatitis $\mathrm{B}$ virus (HBV) and $\mathrm{HCV}$ in colonial Leopoldville [38,71].

Substantial HIV transmission may have happened through these processes; however, some caveats need to be kept in mind. First, an experiment revealed that a simple rinsing with water reduced the probability of retrieving HIV-1 from syringes by 55-80\% [72]. Thus, the $0.6-2.4 \%$ per-reuse probability of transmission of HIV-1 associated with intravenous injections $[60,73]$ could be greatly reduced by the fast procedures described above. Second, in some settings, in addition to rinsing, needles were flushed with distilled water, forcing it through the needle gun, to expel any traces of blood [74], a very simple and fast procedure that probably reduces the risk of HIV transmission even more markedly. Third, meta-analyses of transmission probability after needlestick injuries give mean estimates of 0.75-1.8\% for HCV, which is 2.5-6-times higher than the corresponding value for HIV-1 [44,75,76]. The impact of this transmission route at population level is likely to have been substantially lower for HIV than for HCV, and thus, phylogenetic evidence for HCV spread through needles is not necessarily applicable to HIV spread.

And fourth, the more organized rural injection campaigns against trypanosomiasis were expensive, had extensive associated examinations and mobile laboratory work, and descriptions made by their organizers suggest that hygienic standards were high $[69,70,77]$. For example, even in the early (less well organized) campaigns by Eugene Jamot in Cameroon in the early 1920s, all material was boiled every day [69]. Between injections, most often only fast rinsing procedures were performed. However, in a paper written in 1929 (when his campaigns were better funded and organized), Jamot describes the sterilization rules as follows. All syringes and needles should be boiled every day and additionally the (detachable) needles should be changed between injections [70]. This implies that each injection was most probably performed with a boiled needle not used in another patient since the last boiling. In campaigns against trypanosomiasis and yaws in Sierra Leone, in which several hundreds of patients were being injected in the same place and day, the organizers claimed that "needles are boiled between every injection but syringes are only sterilized initially and not again unless blood should enter from a vein" [77]. This practice might indeed have been possible, if the team had a stock of hundreds of detachable needles which, given their small size, could be boiled together once a day and be each used in only one injection per day. Of course, there was a tendency to describe ideal procedures and, in the real world, sterilization was probably missed in a substantial proportion of injections. Jamot himself recognized his rules had not always been followed by his personnel [70].

The method above would be more likely used in facilities performing no more than dozens of injections per day, since they would need a correspondingly low number of needles, at relatively insignificant extra cost. This was the case of the Leopoldville lazaret for trypanosomiasis patients [66,68].

In high turnover facilities, the standards might have been lower [38]. Overall, it is likely that in many high turnover situations only fast cleaning procedures were performed, and in many cases even these were missed. Still, it should be kept in mind that the necessity of sterilization was well known in early 20th century colonial Africa, and rules for it existed in most health facilities. Unfortunately, no data exist to quantify the proportion of instances where injections were unsafe.

\section{The enhanced heterosexual transmission hypothesis}

The serial transmission hypothesis of adaptation (Figure 1) could also work with sexual transmission. As in the parenteral version, the probability of such an event is higher if exposures are frequent and concentrated in time and space, and if the associated transmission probabilities are higher. The average per-act transmission probability in long series of sex acts is near $0.1 \%$, while it is $0.6-2.4 \%$ per-reuse of intravenous unsterile needles [60,73]. This, and the fact that sex was not a novel factor in Africa, suggest that baseline sexual transmission cannot have accounted for the origin of HIV. 
However, the consideration of genital ulcer disease (GUD) changes this picture. GUD causes inflammation and CCR5 expression in T cells in the donor, thus greatly increasing HIV replication in the genital area and contributing to amplified HIV transmission. In a recipient partner, GUD provides a portal of entry and increases the number of target cells available for HIV. Inflammation in the recipient broadens the range of HIV phenotypes that can successfully establish infection [78]. Thus, GUD greatly contributes to successful transmission by enhancing both HIV transmissibility in the infected and susceptibility in the exposed person [40], and treatment of GUD in either or both is an accepted measure to prevent HIV transmission [51,79]. Genital ulcers also facilitate SIVmac239 acquisition in macaques and speed up its systemic proliferation [80].

HIV-1 transmissibility in sexual acts in which active genital ulcers are present has been estimated in the range 4-43\% per sexual act [53,54]. Based on this, we hypothesized that GUD could have helped serial transmission and initial spread of still ill-adapted zoonotic HIV [40].

Epidemiologists noted early that there is an epidemiological synergy between STD pathogens and HIV [50], and also that amplified transmission of HIV, associated with factors such as STDs, GUDs, acute infection, lack of male circumcision and others play a disproportionate role in the epidemic [51]. We used these concepts to get insight into HIV origins and early spread.

Since GUD is linked to commercial sex work and thus usually flourishes in cities, we reviewed health reports of several colonial cities, focusing particularly on colonial Leopoldville [40], the epicenter of HIV-1-M [27]. Our review indicated that the main GUDs reported for colonial Leopoldville (syphilis, chancroid and lymphogranuloma venereum) were highly epidemic there in 1911-1935 [40]. GUD incidence was probably on the rise already between 1898 and 1910, but colonial reports give insufficient information for this period [40]. Before 1898, Leopoldville was only a small colonial station without railway and so GUD incidence was probably lower. Contacts with southeast Cameroon only became important after 1899 [41]. After 1935, the incidence rates of all reported GUDs (i.e., based on the new cases of primo-secondary syphilis, chancroid and lymphogranuloma venereum) dropped with the mass treatments implemented. These used neoarsenobenzol, bismuthic salts, mercury salts and acriflavine aimed at the whole city population from the early 1930s. Incidence rates declined further with the introduction of antibiotics in 1947, becoming rare in the late 1950s [40]. Incidence of total syphilis had declined only moderately by the 1950 s, but this is counting the very numerous detections of asymptomatic serological cases and tertiary cases $[40,81]$. Counting primary and secondary syphilis cases only (the stages with genital ulcers) the decline was by two orders of magnitude, which is similar to the decline in chancroid and lymphogranuloma venereum. Thus, in the period 1899-1935, GUD incidence was the highest ever recorded for the city, and contacts with southeast Cameroon were important. This period coincides with the tMRCA of HIV-1-M.

We built computer simulations to investigate the possibilities of initial spread of ill-adapted zoonotic HIV-1 (suppressed after acute infection), in Leopoldville in 1919, 1929 and 1958 [40]. The results showed that long chains of transmission during acute infection were far more probable in 1919 and 1929 than in 1958, when the population of the city had grown further, but GUD prevalence had declined. After testing many different scenarios, with variations in the transmission, demographic and other parameters as sensitivity tests, high GUD prevalence emerged as the strongest facilitating factor for initial HIV-1 spread [40]. We thus proposed the enhanced heterosexual transmission hypothesis, which posits that each epidemic HIV strain emerged through the concerted presence in time and space of co-factors helping heterosexual transmission, including the interdependent factors GUD, sexual promiscuity and lack of male circumcision $[40,41,43]$. Enhanced heterosexual transmission is not a new finding, it has extensively been discussed in the past to understand the current HIV pandemic [50,51,53,54]. Our contribution was to apply it to understand the origin of HIV. This hypothesis does not exclude a contribution of parenteral transmission during the initial serial transmission of HIV among humans or in the subsequent early spread among humans [40,41], or any of the other enhancing factors described in a separate section above. The core of this hypothesis is however that without GUD, HIV epidemics would not have taken off.

\section{Critiques to the original 'enhanced heterosexual transmission' simulation model}

Our 2010 model was criticized for using a 43\% per-act transmissibility of HIV-1 with GUD involvement (versus the baseline of $0.1 \%$ ) [81]. However, we used $43 \%$ only when two concomitant co-factors, GUD in the female, and lack of circumcision in the male were present (supported by Cameron et al. [53]). In all other GUD-related situations, we used transmission probabilities in the range 4-7\% (thus with risk ratios above the baseline ranging from 40 to 70). Often, much lower GUD-related risk ratios (e.g., <10) are reported, but these studies asked participants whether they had GUD at any time within a long period (e.g., the last 12 months), a procedure that 
strongly underestimates the per-act GUD effect in acts during which GUD is active (reviewed in [82,83]). Our sensitivity analyses showed that even with all males circumcised (and thus GUD-related transmission probabilities in the range 4-7\%), GUD was crucial to maintain transmission chains of acute infection.

Giles-Vernick et al. [42] pointed out that Leopoldville's prostitutes in early 20th century had a far lower turnover than the 600 client encounters a year that we postulated in our main 2010 model (we used this value based on modern surveys of sex worker behavior [84]). We agree to this, but we note that, in the sensitivity analyses of our model, 600 encounters a year was the maximum (supported by [84]), the range tested included 150 encounters a year, and the main results remained valid in this range [40]. In addition, they claim that Leopoldville's prostitutes had few well known partners with whom they shared food and dwelling (implying a low turnover) [42]. Again, we agree this applied to most women who were labeled as either 'prostitutes' or 'femmes libres', by the colonial administration, but this mild sexual promiscuity was captured in our model by the femmes libres category, which were far more numerous than the commercial sex workers. For example, for 1929, our model assumed 6049 femmes libres (supported by colonial surveys) and only 106 commercial sex workers (only the latter having 150-600 encounters per year) [40].

Our inclusion in the model of high turnover commercial sex workers and their number was realistic: some descriptions of 1930s' Leopoldville suggest their presence in several quarters: many behaved as streetwalkers and had sexual encounters with clients in the bush-covered areas separating the European and African quarters within the city [85].

\section{GUD as a novel factor in tropical rainforest societies}

However, was GUD a novel factor in the relevant regions? Since Africa is now more afflicted by GUD than other continents, this idea seems odd at first sight. In this section, we present evidence that GUDs were virtually absent in most tropical rainforest areas of Central and West Africa (the primary habitat of chimpanzees, gorillas, and sooty mangabeys [2,6,33,40,86-88]) before organized colonialism (post-1885) began.

With prevalence rates in the range 30-80\% [89], herpes simplex virus type 2 (HSV-2) is nowadays a major cause of GUD in Africa. Through genital ulcers, inflammation and interactions with HIV, HSV-2 infection in an HIV-infected or exposed subject greatly enhances both HIV transmissibility and susceptibility, respectively [90,91]. However, its prevalence in 1959 was only $6 \%$ in rural Congo and 21\% in Leopoldville (having tripled since then, following the worldwide trend) [92]. Both the low prevalence and the high urban-rural difference seen in 1959 suggest that HSV-2 prevalence in rural Central Africa, in early 20th century was probably very low.

Several lines of evidence indicate that syphilis and chancroid (caused by the bacteria Treponema pallidum pallidum and Haemophilus ducreyi, respectively) were either absent or rare in Central Africa's rainforest before colonial times. First, reviewers explicitly state the absence of syphilis [93,94]. Second, our review of medical reports of early explorations done when colonial presence was just starting (1885-1905) reveals that syphilis and chancroid were already present in the nascent colonial trading and administrative posts (frequented by colonial troops, traders and commercial sex workers), with a few cases in nearby villages; however, in the villages away from posts, reports mention explicitly that syphilis was absent, and they do not mention chancroid [95,96]. There was evidence of older syphilis presence (e.g., presence of tertiary syphilis) in the towns of the nation states/kingdoms (e.g., Zande, Foulbé) situated near the northern and eastern limits of the equatorial forest block (mainly in savannah or savannah/forest mosaic areas), spread by Arab, Swahili and Hausa traders [40,93,97,98], and in the Atlantic coast, spread by European seafarers $[40,93]$.

We believe these observations are credible for several reasons. First, they were made by trained military doctors who were familiar with STDs and tended to record the observed cases [95,96]. Second, the absence or rarity of these GUDs in tropical forest can be understood in the light of their epidemiology. Computer simulations show that syphilis needs a core group of highly promiscuous people to strive [99,100]. Chancroid is even more tightly linked to commercial sex work than syphilis $[100,101]$. In precolonial societies of the tropical rainforest, high turnover commercial sex workers did not exist [102,103], presumably because these societies seldom had social organization above the level of village or small federations of villages [104]. Thus, we assume that GUDs could not establish stable footholds in these societies despite continued presence on their coastal and savannah borders.

To the north, in the towns situated in grassland, savannah and savannah-forest mosaic areas, commercial sex work existed and GUDs were epidemic $[40,97,98]$. However, in these areas, chimpanzee density was much lower [86, Gagneux P, Pers. Comm.]. In forest-savannah mosaic areas gorillas are not present [88], and sooty mangabeys exist 
only in the forest galleries [87]. Therefore, the overlap between GUD and human exposure to SIVcpz, SIVgor and SIVsmm was minimal in precolonial times.

Both $T$. pallidum and $H$. ducreyi are at least tens to hundreds of thousands of years old in humans including in tropical forested Africa [105,106]. However, venereal syphilis (T. pallidum pallidum) is post-Columbian in Africa: there is phylogenetic and skeletal evidence that it was brought from the New to the Old World in the late 15 th century, by Columbus' crew [105]. The endemic form of T. pallidum in tropical forest Africa before colonialism is $T$. pallidum pertenue (yaws), which does not spread venereally [93,94]. The forms of both T. pallidum pertenue and $H$. ducreyi detected in tropical African areas and Pacific Islands, spread mostly and perhaps exclusively by skin-to-skin contact among children $[93,94,106]$.

Thus, in the areas where human contact with ape and monkey bushmeat is intense, the highly incident GUD seen after 1885 [40,93,95-97] was, like injections and transfusions, a novel factor.

\section{The biogeography of HIV}

Exhaustive collection of fecal samples from many communities of the relevant primates [1,2,5-7], and phylogeographic analyses [6,27,29,32], dramatically improved our knowledge of HIV and SIV biogeography. The SIVcpz/HIV-1 phylogenetic tree reveals that HIV-1-M likely crossed into humans in southeast Cameroon or nearby areas limited by the Sangha-Ngoko-Bumba rivers enclosure [1,2]. The further ignition of HIV-1-M happened in Leopoldville/Kinshasa, and from there the virus spread early on to other cities of Belgian Congo and to neighbouring French Congo and Angola [27,107].

HIV-1-O and HIV-1-P were acquired from G. gorilla gorilla, but the scarcity of locations from which SIVgor was retrieved [1,5] does not permit to pinpoint the site of origin accurately. HIV-1-N originated from SIVcpz found in the Dja river enclosure, south-central Cameroon [2].

HIV-2-A and HIV-2-B are closest to SIVsmm endemic in sooty mangabeys from southwestern Côte d'Ivoire [6]. A phylogeographic analysis of HIV-2-A does not exclude the involvement of either Côte d'Ivoire or Guinea-Bissau for initial spread [29], but Côte d'Ivoire is more likely considering the SIVsmm phylogenetic evidence [6], together with the reported extinction of sooty mangabeys from Guinea-Bissau by the 1940s [33].

\section{Connecting biogeography with data on risk factors}

This improved biogeographical knowledge allowed us to refocus our investigation of risk factors in time and space. Sources suggest that in southeast Cameroon, ape hunting was particularly intense $[41,108]$ and SIVcpz prevalence in wild chimpanzees is about five times the average of $P$. t. troglodytes [2], implying a particularly high zoonotic potential in that area.

In addition, we found that, by 1899 , GUD was already present in the colonial posts of this region, mainly brought by soldiers $[41,95,96]$. By 1911 , thousands of mostly foreign soldiers, porters and rowers were working there for the administration and the main rubber trading company, effectively doubling the number of young men in the area, thus biasing sex ratio and promoting commercial sex work $[41,109]$. Injections were practiced in this period, including atoxyl campaigns against trypanosomiasis and smallpox vaccinations since 1907 [41]. Thus, opportunities for transmission, either parenteral or sexual, existed.

We also documented that the exports from this area were almost exclusively by river directed to either Leopoldville or Brazzaville, and the traffic of ivory and rubber was particularly intense in the period 1899-1923 [41]. A zoonotic HIV-1 strain crossing to humans in southeast Cameroon during this period had the opportunity to migrate to an urban settlement where circumstances existed allowing further spread/adaptation by serial transmission.

Male circumcision is known to provide partial protection from HIV infection to men and shows a strong geographical correlation with HIV-1 prevalence [110]. We made an attempt to correlate HIV biogeography with male circumcision distribution, using an ethnographic approach to obtain information per ethnic group about male circumcision in early 20th century [40,43]. Among the six main Central African cities that could receive SIVcpz-infected migrants, three (including Brazzaville) had $>90 \%$ male circumcision frequency, two (including Leopoldville/Kinshasa) had it in the range 70-90\%, and for one data were lacking. The lower male circumcision frequency of Leopoldville might have contributed to the emergence HIV-1-M in this town, but the data are too scarce for a formal analysis [40]. The sensitivity analysis of our GUD model showed that GUD prevalence explained the data better than male circumcision, with differences in male circumcision frequency not being crucial, but this did not take into account the interdependence of both [40,43]. Indeed, similar as for HIV, GUD acquisition by 
men is inhibited by male circumcision [40,43], and so a lower circumcision rate could have helped HIV to emerge through its effects on GUD.

For HIV-2, the situation is the reverse, sufficient data exist to evaluate the impact of male circumcision, while quantitative GUD data at the level of a city is difficult to find. So far, we have tried to obtain GUD data for the most relevant West African cities during colonial times, as we did for Leopoldville, but we found them only for Dakar [Sousa jD, Unpublished Database]. The evidence for lack of male circumcision as a driving factor is stronger [43]: among 30 cities of West Africa, HIV-2 prevalence in 1985-1991 and male circumcision rates in 1950 were negatively correlated (Spearman rho $=-0.546, \mathrm{IQR}=-0.553--0.546, \mathrm{p} \leq 0.0021$ ); while in most cities male circumcision frequency was, in 1930, >90\%, in Guinea-Bissau and Côte d'Ivoire it was 40-70\%, and these were the only demonstrably early HIV-2-A epicenters [29,43]; the male circumcision rate in Bissau decreased further during the independence war (1961-1974) with the presence of Portuguese troops [43].

In addition, in rural southwestern Côte d'Ivoire where HIV-2 groups A, B, G, H, I likely originated (based on the analysis of SIVsmm sequences [6,7]), male circumcision was uncommon in early 20th century, while it was universal in almost all the remaining sooty mangabey range. We, therefore, suggested that lack of male circumcision may have helped serial transmission and partial adaptation of HIV-2-A and HIV-2-B in this area [43]. The impact of lack of male circumcision in this process could have been direct and/or indirect through its effect on GUD incidence.

\section{Comparison of hypotheses}

Transmitted viral diversity \& initial adaptation of SIV to humans

During serial transmission of SIV between humans, adaptation could be facilitated by transmitted viral diversity. Transmission through transfusion results in very high levels of transmitted viral diversity. In approximately $40 \%$ of HIV-1 intravenous transmissions and approximately $20 \%$ of sexual transmissions several variants are transmitted [111]. However, sexual transmission of HIV-1 diversity is substantially more common if the exposed person has genital ulceration [112]. Thus, both GUD and unsafe intravenous injections would allow many transmissions of multiple diverse viral variants, while transfusions would be the most efficient in this regard.

\section{Risk factors in the early colonial posts}

Wild chimpanzee populations collapsed more steeply after approximately 1950, suggesting intensified hunting after that time (reviewed in [41]). However, several sources indicate intense chimpanzee hunting also in the early 20th century $[41,108,109]$.

The colonial posts established in the inner forest (1885-1910), although no larger than villages, had a radically different social life, with a biased sex ratio and sexual promiscuity. There, GUD spread rapidly [93,95]. Some posts (but not all) had one doctor and/or one or two nurses [93]. For this early period and for interior posts, we often know the approximate timing of the first injection campaigns (broadly speaking, smallpox vaccinations after approximately 1890, atoxyl against trypanosomiais after approximately 1905, neoarsenobenzol against syphilis and yaws after approximately 1911-1920), and of the earliest reports of GUD. As we reviewed above, the standards of needle hygiene in these posts were probably low.

However, the reports seldom quantify GUD or injections in the posts, in this period [41,93,95-97,109]. In addition, both GUD and injections were highly correlated, not only on a microspatial level (e.g., present in the posts themselves, absent in nearby villages [95,96]), but also on a social level (e.g., Africans working directly for the colonial administration were both more likely to be GUD-infected and treated by injections [93]). Because of this, if SIV was transmitted between humans in these posts, GUD and injection intensity were correlated, and may have acted in concert to allow additional spread of HIV.

\section{Risk factors in the cities}

For the cities, the available data are far more complete, in several respects. First, there are colonial reports quantifying the annual number of GUD cases (and even the proportion of syphilis cases that are primosecondary, and hence associated with genital ulcers), and of diseases treated by injections [40,61,68] [SOUSA JD, UnPublished Database]. Second, demographic data detailing the city population, partitioned by gender and adults/children and sometimes by ethnic group, are available $[40,43]$. Third, urban dwellers were tightly controlled and health facilities were well staffed, making underreporting or misdiagnosing of disease a lesser problem. This allowed us to infer more reliable incidence rates for GUDs in Leopoldville (1911-1958) [40]. We found that primosecondary syphilis, chancroid 


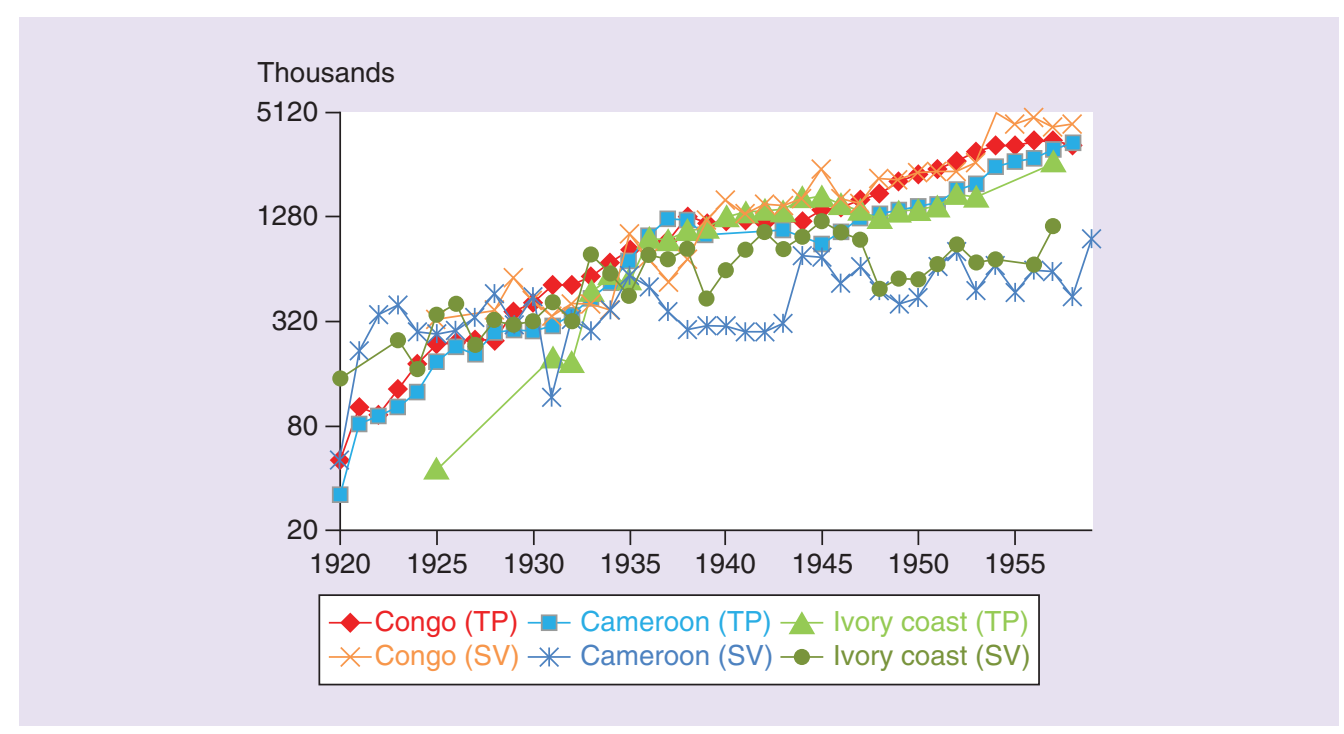

Figure 2. Progression of healthcare in Central and West Africa. The progression of the number of treated patients (excluding vaccinations) for any condition (TP) and the number of smallpox vaccinations in the three African colonies more relevant to HIV-1 and HIV-2 origins.

Based on colonial reports [SOUSA JD, UNPUBLISHED DATABASE].

and lymphogranuloma venereum peaked in this city in 1910-1935 and then their incidence rates declined by two orders of magnitude until the late 1950s [40]. After we published this study, we gathered data for other cities, albeit not as complete as for Leopoldville, and the pattern is broadly similar [sousA JD, UNPUBLISHED DATABASE]. Peak GUD time roughly coincided with the tMRCAs of all main HIV groups [40,24-30], consistent with a critical role for GUD-enhanced heterosexual transmission.

These timings of GUD incidence are explained by healthcare patterns. Leopoldville grew fast in the period 1918-1929, with many men being recruited to work in infrastructure construction, which generated a 3:1-4:1 sex ratio and favored sex work, at a time of incipient healthcare [40]. Only in the period 1929-1935, after the Croix Rouge STD clinic opened, did mass screening permit to treat nearly all syphilis-infected people in Leopoldville with neoarsenobenzol and bismuthics. Effective treatment against chancroid and lymphogranuloma venereum came only in the late 1930s with sulfonamides, and then improved after 1947 with antibiotics [40,61,81].

City growth was essentially exponential throughout the entire 20th century [40]. Injections also increased exponentially, as the health system reached more patients, and expanded in resources and variety of treatments $[35,40,41]$. Overall, the number of treated patients was two orders of magnitude higher in the late 1950s than in the 1920s (Figure 2).

Organized transfusion services and programs were established in the 1950s in most colonies and the number of transfusions increased in the following decades. Only sporadic reports of transfusions exist for the 1920s and 1930s [39]. Needle and syringe sterilization standards deteriorated after approximately 1960, when independence caused most qualified health personnel to leave these countries [35]. Therefore, parenteral risks were much higher shortly after colonial independence compared with early 20th century.

Parenteral risks were not peaking at the timing of tMRCAs of all epidemic HIV groups, they continued to rise for at least another half century. Thus, if injections were a critical factor, one would expect many more epidemic HIV groups starting after mid 20th century than in early 20th century. HIV-1-N originated in mid 20th century [31], and the same may apply to HIV-1-P [4], but they are rare (together $<20$ cases found) and not well adapted $[1,4]$ (i.e., they are not Stage 5 infections). No other epidemic HIV groups were identified after massive efforts of screening tens of thousands of HIV seropositive samples from Cameroon with peptides of all HIV-1 groups and many SIVs $[4,14,15,113]$. Therefore, we propose that short parenteral serial transmission events, parenteral outbreaks and other forms of parenteral hypotheses, even if contributing to partial HIV adaptation, and even if necessary to give rise to epidemic HIV, are unlikely to be sufficient to promote the level and kind of adaptation needed to become a self-sustaining Stage 5 human sexually transmitted pathogen. 


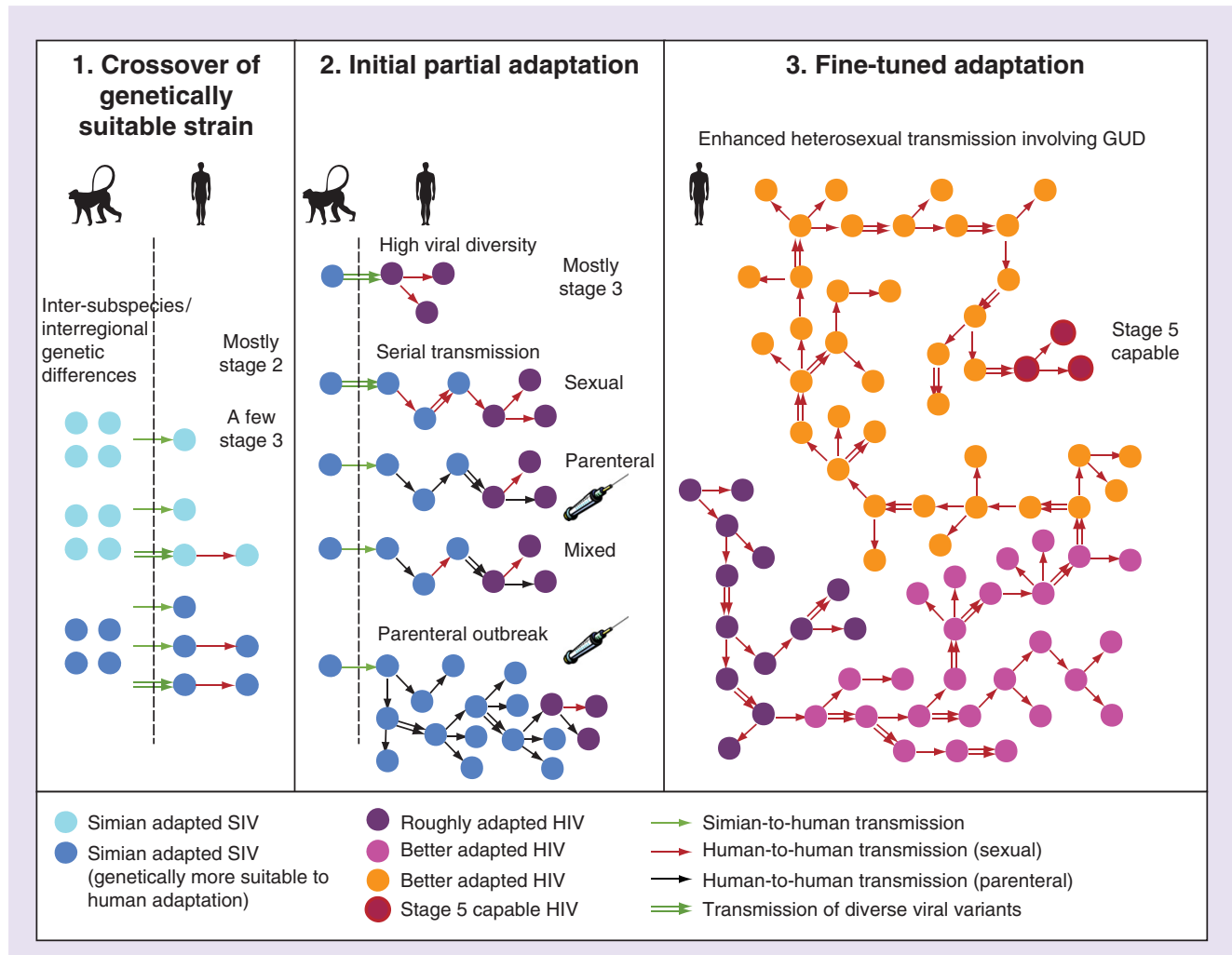

Figure 3. A three-step model for HIV adaptation and emergence. The three panels illustrate our proposed three steps in HIV adaptation and emergence. In Step 1, there is a simian-to-human transfer of SIV genetically suitable to adapt to humans. In Step 2, we outline several alternative (not mutually exclusive) processes potentially generating rough HIV adaptation. In Step 3, enhanced heterosexual transmission involving GUD produces a Stage 5 capable HIV strain.

GUD: Genital ulcer disease; SIV: Simian immunodeficiency virus.

\section{A three-step model for HIV adaptation \& emergence}

In Table 1, we list the factors potentially contributing to SIV adaptation to become HIV, and arguments over the possible sufficiency of each factor to allow HIV to reach full adaptation (i.e., the level and kind of adaptation necessary to reach Stage 5 as an STI). As the Table shows, if any of the factors $1-4$, or any combination of them were sufficient, HIV epidemics would have emerged continuously over millennia, much like in the case of HTLV. If any of the parenteral factors (5-8), or any combination of one of them with factors $1-4$ were sufficient, we should observe many more Stage 5 HIVs emerging from mid 20th century onward. To explain the time paradox of epidemic HIV emergence and be fully compatible with all observations, there is no other existing hypothesis than one that includes GUD. In absence of other evidence, the most plausible explanation for full adaptation would have to include long chains of sexual transmission involving GUD (factor 11), whether or not in combination with some of the parenteral or other factors.

Based on the arguments expressed so far, the phylogenetic patterns of SIV and HIV, the existing evidence about factors potentiating adaptation and the co-factor effects on HIV transmissibility, we propose the following three-step model for HIV adaptation and Stage 5 emergence (illustrated in Figure 3).

\section{Step 1}

There was a simian-to-human transfer of a SIV that had higher genetic potential to adapt to humans. There is evidence that such selection happened, at least for HIV-1-M: SIVcpz of P. t. troglodytes is fewer mutational steps away from both evolving a human-adapted amino acid in the Gag30 site (enabling human tetherin antagonism) than SIVcpz of P. t. schweinfurthii. In addition, SIV cpz from southeast Cameroon sites requires fewer mutational steps for this adaptation than SIVcpz from most other Cameroonian locations [3]. We hypothesize that similar 


\begin{tabular}{|c|c|c|c|c|}
\hline $\begin{array}{l}\text { Factors potentially contributing to biological } \\
\text { adaptation of SIV to humans }\end{array}$ & $\begin{array}{l}\text { Estimated temporal pattern of } \\
\text { factor }\end{array}$ & $\begin{array}{l}\text { Prediction for temporal } \\
\text { distribution of epidemic HIV } \\
\text { origins if the factor alonewas } \\
\text { sufficient to Stage } 5 \text { transition }\end{array}$ & Other arguments & $\begin{array}{l}\text { Consistent } \\
\text { with } \\
\text { evidence }\end{array}$ \\
\hline \multicolumn{5}{|l|}{ Present in precolonial era (before 1885) } \\
\hline $\begin{array}{l}\text { 1. SIV preadaptation } \\
\text { Some SIVs are more preadapted to human infection } \\
\text { than others, e.g., within } \operatorname{SIV} \mathrm{cpz} \text {, the ancestors of } \\
\text { HIV-1-M are more preadapted than other strains }[1,3]\end{array}$ & $\begin{array}{l}\text { Pattern not expected to differ } \\
\text { since millennia }\end{array}$ & $\begin{array}{l}\text { Multiple emergences during } \\
\text { millennia }\end{array}$ & & No \\
\hline 2. Individual host genetic factors & $\begin{array}{l}\text { Pattern not expected to differ } \\
\text { since millennia }\end{array}$ & $\begin{array}{l}\text { Depending on frequency of the } \\
\text { specific host genetic factor, } \\
\text { potential emergence stable } \\
\text { during millennia }\end{array}$ & & No \\
\hline $\begin{array}{l}\text { 3. Viral diversity transmitted } \\
\text { Experiments suggest it can be relevant [47-49] }\end{array}$ & $\begin{array}{l}\text { Relatively common during } \\
\text { exposure to bushmeat; likely } \\
\text { repeatedly during millennia }\end{array}$ & $\begin{array}{l}\text { Multiple emergences during } \\
\text { millennia }\end{array}$ & & No \\
\hline $\begin{array}{l}\text { Combinations of factors } 1-4 \\
\text { e.g., } 1+2,1+2+3,1+2+4 \text {, etc. }\end{array}$ & $\begin{array}{l}\text { Pattern not expected to differ } \\
\text { since millennia }\end{array}$ & $\begin{array}{l}\text { Depending on the likelihoodof } \\
\text { the required combination of } \\
\text { factors, occasional emergence } \\
\text { during millennia }\end{array}$ & $\begin{array}{l}\text { It cannot be excluded that } \\
\text { occasional short-lived HIV } \\
\text { epidemics might have } \\
\text { taken place in the past }\end{array}$ & Unlikely \\
\hline \multicolumn{5}{|l|}{ Present in colonial and postcolonial era (after 1885) } \\
\hline $\begin{array}{l}\text { 5. Serial transmission through unsafe injections } \\
\text { Serial passage experiments suggest it can be } \\
\text { relevant }[35,59]\end{array}$ & $\begin{array}{l}\text { Injections } 2 \text { orders of } \\
\text { magnitude more common in } \\
\text { late } 1950 \text { s than in } 1920 \text { s; } \\
\text { sterilization standards worse } \\
\text { after } \sim 1960\end{array}$ & $\begin{array}{l}\text { Many more Stage } 5 \text { emergences } \\
\text { starting in mid } 20 \text { th century } \\
\text { than in early } 20 \text { th century - the } \\
\text { opposite is observed }\end{array}$ & & Unlikely \\
\hline $\begin{array}{l}\text { 6. Serial transmission through transfusions } \\
\text { Serial passage experiments suggest it can be } \\
\text { relevant }[35,59]\end{array}$ & Transfusions rare before 1950 & Same as in 5 & $\begin{array}{l}\text { Tranfusions allow maximal } \\
\text { viral diversity transmitted }\end{array}$ & Unlikely \\
\hline 8. Massive parenteral transmission & Same as in 5 & Same as in 5 & $\begin{array}{l}\text { Injection intensity of rural } \\
\text { campaigns much lower } \\
\text { than in IVDUs [41] }\end{array}$ & Unlikely \\
\hline $\begin{array}{l}\text { Combinations of factors } 1-8 \\
\text { e.g., } 1+5,1+3+5,1+3+6 \text {, etc. }\end{array}$ & Far more common after 1950 & Same as in 5 & & Unlikely \\
\hline $\begin{array}{l}\text { 9. Sexual serial transmission enhanced by GUD } \\
\text { Serial passage experiments suggest it can be } \\
\text { relevant }[35,59]\end{array}$ & $\begin{array}{l}\text { GUD almost absent before } \\
\text { 1885; far more common in } \\
\text { colonial cities in the period } \\
\text { 1900-1935; } 2 \text { orders of } \\
\text { magnitude less common in late } \\
\text { 1950s }\end{array}$ & $\begin{array}{l}\text { More Stage } 5 \text { emergences } \\
\text { starting in early 20th century, } \\
\text { as is observed }\end{array}$ & $\begin{array}{l}\text { These chains may have } \\
\text { been common and HIVs } \\
\text { are rare }\end{array}$ & Less likely \\
\hline $\begin{array}{l}\text { 10. Long chain of sexual transmission, enhanced by } \\
\text { sex work, with GUD rare }\end{array}$ & $\begin{array}{l}\text { More brothels and high } \\
\text { turnover sex workers after } \\
1960[38]\end{array}$ & Same as in 5 & $\begin{array}{l}\text { Simulations suggest sex } \\
\text { work less important than } \\
\text { GUD [40] }\end{array}$ & Less likely \\
\hline $\begin{array}{l}\text { 11. Long chain of sexual transmission, enhanced by } \\
\text { GUD }\end{array}$ & Same as in 9 & Same as in 9 & $\begin{array}{l}\text { Simulations show this is } \\
\text { possible even with } \\
\text { ill-adapted HIV [40] }\end{array}$ & Yes \\
\hline $\begin{array}{l}\text { Combinations including } 11 \\
\text { e.g., } 1+2+10+11,1+3+5+11,1+3+6+11,1 \\
+3+9+10+11 \text {, etc. }\end{array}$ & $\begin{array}{l}\text { Peak in } 1910-1935 \text { if GUD was } \\
\text { the crucial factor }\end{array}$ & Same as in 9 & $\begin{array}{l}\text { Several factors other than } \\
\text { GUD (e.g., factor } 1 \\
\text { probably played a } \\
\text { role }[1,3] \text { ) }\end{array}$ & Yes \\
\hline \multicolumn{5}{|c|}{$\begin{array}{l}\text { In the leftmost column, we list the factors/combinations of factors that could have contributed to SIV/HIV adaptation to the human host, with references supporting a possible role } \\
\text { in adaptation. In the second column, we list their temporal patterns. In the third column we list what would be the temporal pattern of Stage } 5 \text { HIV emergences observed if that } \\
\text { factor/combination alone was sufficient to let HIV transition to Stage } 5 \text {. In the fourth column we add other relevant arguments. The rightmost column contains our evaluation of the } \\
\text { plausibility of each factor/combination alone having been sufficient for epidemic emergence and thus being consistent with the observed pattern of origins of the four Stage } 5 \text { HIVs. } \\
\text { GUD: Genital ulcer disease; IVDU: Intravenous drug user; SIV: Simian immunodeficiency virus. }\end{array}$} \\
\hline
\end{tabular}


intersubspecies and interregional genetic differences in SIV suitability to human adaptation might have played a role in the origin of the other HIV groups as well.

\section{Step 2}

After crossover, the virus may have partially adapted to the human host, helped by a high transmitted viral diversity (e.g., due to a large inoculum or multiple bushmeat exposures), the plausibility of which is suggested by experiments [47-49]. Another factor that may cause partial adaptation is a possible short chain of serial transmission between acutely infected people [35,36,59]. This could have been sexual, parenteral or mixed (Figure 3). A sudden parenteral outbreak fueled by parenteral risk factors concentrated in time and space may also help adaptation, by multiplying the number of hosts in which SIV can 'explore' favorable mutations. We do not know which of these factors operated for each HIV group, and so we take the pluralistic view that any combination of such factors may be sufficient for the partial adaptation (Figure 3, center). However, whatever the mechanism, we believe this step only generated partial adaptation, not capable of Stage 5 emergence, based on the timing arguments we presented so far (summarized in Table 1). In its current state, HIV-1-N could be an example of such a Stage 3 or Stage 4 pathogen.

\section{Step 3}

After partial adaptation, a long chain of enhanced heterosexual transmission with GUD involvement allowed the strain to gradually fine-tune its adaptation until attaining Stage 5 as an STI. We consider this a necessary step for full adaptation, because of the timing arguments we discussed: highly incident GUD was the only risk factor that peaked in early 20th century colonial cities and then faded away, and because all four epidemic HIV groups are primarily STIs, and not mainly parenterally transmitted viruses like HCV. Although parenteral passages might have been important initially to imbue the virus with a general adaptation to host target cells and restriction factors, enhanced sexual transmission was likely necessary to allow for sexual passages, which would allow the virus to better adapt to be transmitted by this route. We believe a long chain, of dozens, perhaps up to a couple of hundreds of transmissions was necessary because: if just a few were sufficient, then this step would be essentially similar to the short-chain serial transmission scenarios, and such events had ample opportunities to happen by the parenteral route, after mid-20th century, and no well-adapted HIV resulted (Table 1); a long chain is a larger scale event, thus less common than short chains, which is consistent with the scarcity of Stage 5 HIVs. The presence of GUD makes it more likely that various diverse viral variants are transmitted [112] (illustrated in Figure 3, right). Our simulations showed that such long chains are possible even with an ill-adapted HIV, and that GUD is the most crucial factor for them to happen [40].

Non-GUD STIs such as those causing urethritis and vaginal discharge might have also played a role, because although they are associated with a lower co-factor effect on HIV transmission [79,114], they were more prevalent than GUDs and their peak coincided with the peak of GUD [SousA JD, UNPUBLISHED DATABASE].

\section{Discussion \& open points}

The timing of the origin of epidemic HIVs, in comparison with other viruses, implies that novel enabling factors were involved starting in late 19th-early-20th century. Large population agglomerations and use of firearms were not novel in the rainforest $[57,58]$. However, the social changes associated with colonial cities were novel, and they played a role by promoting commercial sex work and GUD. Intense GUD existed in towns situated in savannah areas before 1885 [97,98], but human contact with chimpanzees and sooty mangabeys was far lower there. Thus, highly incident GUD was a novel factor in the most relevant habitats.

Injections and transfusions were also novel factors. There are only sporadic reports of transfusions in the 1920s [38,39,42]. However, additional archival research may reveal transfusions that were not discussed in the published literature, and so the transfusion hypothesis of adaptation (a variant of the Parenteral Serial Transmission Hypothesis) remains worth considering. Parenteral transmission has been documented in modern IVDUs and hospital outbreaks [41,60]; however, the average injection intensity in early-20th century African communities was far below the levels seen in modern parenteral outbreaks, lower than currently required for HIV-1 to have $\mathrm{R}_{0}>1$. Yet certain subsets of hospital/clinic patients received many injections, which leads to the parenteral outbreak hypothesis, whereby the virus spread parenterally to dozens of patients, enhancing its chances of acquiring favorable mutations. However, this hypothesis depends crucially on: the still ill-adapted virus having landed in patient communities where injection frequency was high; substantial levels of nonsterilization of needles. In early- 
20th century, high frequency of injections per patient existed in Leopoldville, in the 1920s, in the trypanosomiasis lazaret [66,68], in the main hospital, and in the Croix Rouge STD clinic from 1929 onward [38,61,81], with sterilization standards probably being lower in the latter [38].

Under this scenario, the four epidemic groups of HIV would require four such events: one in either southeast Cameroon or Leopoldville/Kinshasa, to explain HIV-1-M, another in Cameroon to explain HIV-1-O, and two others in Côte d'Ivoire to explain HIV-1-A and HIV-1-B, all in a two decade's period, and no such events in mid-20th century, when hospital populations were much larger, and many more injections and transfusions were administered. The concentration of the emergence of four HIV groups in a short time window would be left unexplained (Table 1).

In contrast, in the frame of the enhanced heterosexual transmission hypothesis, the temporal coincidence between the emergences of the four groups of HIV is an integral part of the hypothesis, and mirrors the temporal coincidence of high intensity of sexual transmission co-factors in most colonial cities. There was a rush to build infrastructure, producing organized hiring of male workers, and thus a male-biased sex ratio, which promoted commercial sex workers and milder forms of sexual promiscuity (e.g., the so-called femmes libres) [38,40,85]. This situation ignited GUD epidemics, at a time when mass treatments were not yet available. The latter came only in the early 1930s and, for chancroid and lymphogranuloma venereum, they could only be effective with the introduction of sulfonamides in the late 1930s [40]. In addition, this was a time of lower male circumcision frequency in many Central and West African cities, including Leopoldville and Abidjan [40,43].

We did not investigate the role of traditional practices among Central African women that involve the use of herbal agents in the vagina to enhance sexual experience. This practice produces genital irritation and inflammation, and has been hypothesized to contribute to HIV spread [115,116]. It is unclear whether this contributes significantly to the HIV epidemic [116]. Since the practice is likely old, it could have increased the odds of HIV emergence before GUD became epidemic. Further studies are needed to determine the frequency and duration of such inflammation, and their impact on HIV per act transmissibility.

HIV-1-N and HIV-1-P, probably arose in mid-20th century [4,31]. Their rarity and the apparent lack of other groups starting from that epoch, after a two-decade-long massive screening effort performed in Cameroon $[4,14,15,113]$, argue that few HIV strains emerged in that time frame. Even if new ones are still to be discovered, they are not expected to be better adapted than these two rare groups, or else we should have been able to detect them already. This absence of Stage 5 well-adapted strains emerging after approximately 1950 is not easy to explain if we assume that parenteral risks were the critical factors, because injections and transfusions were far more common at that time than they had been $2-3$ decades earlier $([35,39,41]$; Figure $2 \&$ Table 1$)$. Even assuming that needle sterilization standards were worse in early compared with mid-20th century, there was a worsening of standards again after approximately 1960 [35]. Also, cities were much larger, and growing exponentially, implying more rural immigrant arrivals per unit of time.

This suggests that parenteral risks alone were not a sufficient factor (Table 1), although they could have been necessary and complemented by another factor. The best candidate for that additional factor is enhanced heterosexual transmission in cities with high GUD incidence. The absence of well-adapted HIV emergence after the mid-20th century is consistent with the steep decline of bacterial GUDs [40], still low levels of HSV-2 [92] and high male circumcision frequency $(>90 \%)[40,43]$.

Therefore, the Parenteral Serial Transmission and/or the parenteral outbreak hypotheses on their own are not able to explain the emergence of epidemic HIVs. We proposed a three-step model instead, by which these factors may still have been necessary, but had to be complemented by enhanced heterosexual transmission (see last section and Figure 3).

In recent decades, HSV-2 became an important cause of genital ulcers in Africa [89,92]. The enhanced heterosexual transmission hypothesis would predict this situation to spark new HIV epidemic groups, but no epidemic HIV group appears to be dated from that time frame, generating a difficulty for the hypothesis. We can think of two reasons for this. First, HSV-2 causes short chronic ulcer duration $(<1$ week $)$ and this may not favor serial transmission because an individual acquiring ill-adapted SIV/HIV through an HSV-2 ulcer will have his/her ulcer healed before HIV achieves high viral load, and will thus not transmit further. Here a cautious note is needed: there is evidence that HSV-2 infection causes continued genital inflammation past the healing of ulcers, potentially affecting HIV transmissibility and susceptibility for longer than the duration of recurrent ulcers [117]. However, if we accept that the effect of HSV-2 on HIV transmissibility and susceptibility is mainly when ulcers are active, as has been proposed by several modeling studies [79,114], our argument above holds. 
Second, the high prevalence of HIV-1-M in core transmitters seen after approximately 1990 may thwart new HIV emergence by partial inhibition of superinfection [118] or elimination of core transmitters through AIDS. Alternatively, there may not have been sufficient time for such an HIV to have spread enough to be detected.

Further research will be needed to understand the relative contributions of sexual and parenteral transmission to the origin and early spread of HIV. Another interesting research question is to understand whether, after transmission to the first human, each HIV group was initially transmitted in the nearby forest posts or whether it was brought directly to a city by the index case.

Understanding the factors that permitted HIV groups to emerge may be important to prevent new SIVs to take hold in the human population, and it may provide a template to understand the zoonotic origins of other major human infectious diseases [13]. A high spatial and temporal concentration of co-factors of transmission may, for example, be important also to evaluate whether Ebola outbreaks could spark a pandemic. Some outstanding questions and prospects for future research are summarized in theFuture perspective section.

In conclusion, both the parenteral and the sexual hypotheses provide plausible explanations for the initial adaptation of HIV groups. Further adaptation and spread by enhanced heterosexual transmission was probably necessary (Figure 3). The enhanced heterosexual transmission hypothesis proposes a major role for a combination of the co-factors of heterosexual transmission (GUDs, STDs, commercial sex work and lack of male circumcision). Such factors likely allowed the adaptation of HIV to become a human STI, rather than a mainly parenterally transmitted pathogen like HCV. The timing of peak GUD and relatively low male circumcision in cities fits the tMRCAs better than other proposed enabling factors (Table 1). By emphasizing heterosexual transmission, which currently overwhelmingly dominates the HIV epidemic [44,45], without the need to invoke additional factors, this hypothesis thus fulfills the principle of parsimony [40,41]. In any case, the emergence of HIV needed novel enabling factors, and all the credible ones we reviewed were associated with societal changes during early colonial rule.

\section{Future perspective}

To tackle the unsolved questions we outlined here, further virological research can be done:

- New phylogeographic studies may reveal the early epicenters of HIV-1-O and HIV-2-B, and remove the uncertainty about the HIV-2-A epicenter [29]. This is going to require more viral sequences from diverse locations;

- Further detection and sequencing of 'fossil' HIV strains from old sera and/or biopsy samples, similar to studies already done [26] may permit to narrow down the uncertainty boundaries of the tMRCAs. Several such projects are ongoing;

- Better recombination analyses of early strains may help to understand whether recombination, either between two bushmeat-acquired SIVs in the same human, or between strains already infecting several humans played a role in the initial adaptation of each HIV group;

- Screening more samples from humans exposed to bushmeat (expanding on $[7,14,15]$ ), using peptides from all HIVs and many SIVs will likely detect new zoonotic human SIV/HIV infections. In most infections detected by serology, virus retrieval is unlikely $[14,15]$. However, if virus is retrieved in some cases (arguably this is the situation of some rare HIV-2 groups [6,7]), it could help us understand how the epidemic groups originated (e.g., whether the virus can sometimes remain infectious beyond acute infection even without adaptation by serial transmission);

- More extensive sampling and sequencing of SIVcpz, SIVgor and SIVsmm from wild primates may pinpoint the geographical origin of each HIV group more precisely. Research might be confounded by ape and monkey movements during the last century, and by the shrinking of the simian populations due to human activity; some of the relevant SIV lineages might have disappeared entirely; In addition, additional research in nonvirological fields can be combined fruitfully with the evidence gathered in the projects above, as follows.

- New archival, colonial historical and anthropological research could be done about bushmeat practices, sexual and parenteral risk factors, demography and transportation networks. Several studies have already followed these paths $[27,34-43,71,81]$, and future advancements in virological knowledge (points 1-5) could further refine the temporal and spatial focus of such analyses, improving their effectiveness; 
- The data about risk factors might be used in epidemiological simulations (extending on [40]), modeling both sexual and parenteral transmission and, thus, estimating the relative contributions of either forms of transmission to HIV adaptation and initial spread.

Acknowledgements

The authors thank P Dandoy and R Storme (Afrika Archief, Federale Overheidsdients - Buitenlandse Zaken, Buitenlandse Handel en Ontwikkelingssamenwerking, Brussels, Belgium), E Camara (Archives Nationales d'Outre-Mer, Aix-en-Provence, France) and A

Executive summary

Evidence for HIV adaptation \& novel enabling factors

- All four main epidemic HIV groups' origins are dated to the late 19th-early-20th century, contrasting with the antiquity of human T-cell lymphotropic viruses and other viruses.

- Simian immunodeficiency virus (SIV) antibodies are present in 8-17\% of HIV-negative Central Africans who hunt or butcher bushmeat, without giving rise to new strains of HIV.

- SIV is estimated to be at least 77,000 years old, and hunting and butchering of SIV-carrying primates has been common practice throughout human history.

- Therefore, there were ample opportunities for SIV to cross to humans during millenia.

- This suggests that HIV emergence was enabled by novel factors allowing adaptation of SIV to be sexually transmitted among humans; these factors must have arrived to the habitats of chimpanzees, gorillas and sooty mangabeys after late 19th century.

Proposed novel enabling factors (post late 19th century)

- Large population agglomerations and firearms were not novel in inner Central Africa.

- Unsterile injections or transfusions were novel, and could have helped SIV to adapt to humans by parenteral serial transmission.

- We proposed as critical factor enhanced heterosexual transmission by spatial and temporal concentration of commercial sex work, genital ulcer disease (GUD) and lack of male circumcision.

- We demonstrate that highly incident GUD was a novel factor in the rainforest, starting with the establishment of colonial posts.

Review of the evidence relevant to evaluate the different hypotheses

- Unsterile injections, GUD and transfusions all had the potential to facilitate SIV adaptation to humans.

- In colonial cities, GUDs were highly incident in the early-20th century, and then dramatically declined with mass treatments. Their peak in cities coincided with lower male circumcision frequency, and with the origin of the epidemic HIV strains.

- Our previous model showed the plausibility of GUD-associated serial transmission of ill-adapted HIV-1. We address criticisms to the model.

- In early-20th century, injection frequency was high only for smaller groups of patients. Transfusions became widespread only after approximately 1950.

- Parenteral risks increased exponentially, following development of healthcare systems, peaking after 1950. Sterilization standards worsened after independence of the colonies before getting better in the last two decades.

- Strong evidence indicates the dominant role of parenteral transmission for $\mathrm{HCV}$, and this transmission route might have been crucial also for its emergence. However, in contrast to HCV, HIV is mainly an STI, with much lower parenteral transmission risk, and the findings on HCV cannot be automatically extrapolated to HIV.

\section{Conclusion}

- Early-20th century injection campaigns are unlikely to have spread HIV massively, to a degree seen in modern intravenous drug users, but could have facilitated early serial transmission events.

- The fact that the HIV groups starting after 1950 did not spark epidemics, when injections, transfusions, rural-urban migration and bushmeat intensity peaked, suggests that parenteral serial transmission, even if necessary, was not sufficient for epidemic emergence.

- Enhanced heterosexual transmission fits not just the start, but also the end of the time window of HIV epidemic origins, because after 1950 GUD was subdued and male circumcision was almost universal in most relevant cities.

- We thus propose that enhanced heterosexual transmission was the main driver of HIV adaptation and emergence, even if parenteral serial transmission also contributed to the initial steps of adaptation. We propose a three-step model for HIV adaptation: an initial crossover of genetically preadapted SIV, followed by small scale events generating partial adaptation, and then long chains of heterosexual transmission allowing full adaptation to be a Stage 5 STI. 
Pueyo (Institut de Médecine Tropicale du Service de Santé des Armées, Marseille, France) for their support throughout the years during our research in their respective Archives.

The authors are grateful to A Abecasis (Instituto de Higiene e Medicina Tropical, Portugal), T Avelar, A Buvé (Instituut voor Tropische Geneeskunde, Belgium), R Jorge Camacho (KU Leuven, Belgium), N Rodrigues Faria (University of Oxford, UK), P Havik (Instituto de Higiene e Medicina Tropical, Portugal), B Hewlett (Washington State University Vancouver, USA), P Lemey (KU Leuven, Belgium), M Temudo (Universidade de Lisboa, Portugal), and M Worobey (The University of Arizona, USA) for enlightening discussions.

Financial \& competing interests disclosure

The research done by JD Sousa and A-M Vandamme in this study has been supported in part by grant G.0692.14, funded by the Fonds voor Wetenschappelijk Onderzoek - Flanders (FWO, http://www.fwo.be/en/), Belgium. While contributing to this study, $\checkmark$ Müller was a Fellow of the Parmenides Center for the Conceptual Foundations of Science, part of Parmenides Foundation (www.parmenides-foundation.org/home/), Germany. He was supported by the grant GINOP-2.3.2-15-2016-00057 (Az evolúció fényében: elvek és megoldások). The authors have no relevant affiliations or financial involvement with any organization or entity with a financial interest in or financial conflict with the subject matter or materials discussed in the manuscript. This includes employment, consultancies, honoraria, stock ownership or options, expert testimony, grants or patents received or pending, or royalties.

No writing assistance was utilized in the production of this manuscript.

\section{Open access}

This work is licensed under the Attribution-Non Commercial-No Derivatives 4.0 Unported License. To view a copy of this license, visit http://creativecommons.org/licenses/by-nc-nd/4.0/

\section{References}

Papers of special note have been highlighted as: $\bullet$ of interest; $\bullet \bullet$ of considerable interest

1 Sharp PM, Hahn BH. Origins of HIV and the AIDS pandemic. Cold Spring Harb. Perspect. Med. 1, a006841 (2011).

2 Keele BF, Van Heuverswyn F, Li Y et al. Chimpanzee reservoirs of pandemic and nonpandemic HIV-1. Science 313(5786), 523-526 (2006).

3 Li Y, Ndjango J-B, Learn GH et al. Eastern chimpanzees, but not bonobos, represent a simian immunodeficiency virus reservoir. J. Virol. 86(19), 10776-10791 (2012).

4 Vallari A, Holzmayer V, Harris B et al. Confirmation of putative HIV-1 group P in Cameroon. J. Virol. 85(3), 1403-1407 (2011).

5 D'arc M, Ayouba A, Esteban A et al. Origin of the HIV-1 group O epidemic in western lowland gorillas. Proc. Natl Acad. Sci. USA 112(11), E1343-E1352 (2015).

6 Santiago ML, Range F, Keele BF et al. Simian immunodeficiency virus infection in free-ranging sooty mangabeys (Cercocebus atys atys) from the Tai forest, Côte d'Ivoire: implications for the origin of epidemic human immunodeficiency virus type 2. J. Virol. 79(19), 12515-12527 (2005).

7 Ayouba A, Akoua-Koffi C, Calvignac-Spencer $S$ et al. Evidence for continuing cross-species transmission of SIVsmm to humans: characterization of a new HIV-2 lineage in rural Côte d'Ivoire. AIDS 27(15), 2488-2491 (2013).

8 Hunt JC, Brennan CA, Golden AM et al. Molecular aAnalysis of HIV-1 Group O and HIV-2 variants from Africa. Leukemia 11(Suppl. 3), 138-141 (1997).

9 Smith SM, Christian D, de Lame V et al. Isolation of a new HIV-2 group in the US. Retrovirology 5, 103 (2008).

10 Gottlieb GS, Eholié S-P, Nkengasong JN et al. A call for randomized controlled trials of antiretroviral therapy for HIV-2 infection in West Africa. AIDS 22(16), 2069-2072 (2008).

11 Locatelli S, Peeters M. Cross-species transmission of simian retroviruses: how and why they could lead to the emergence of new diseases in the human population. AIDS 26(6), 659-673 (2012).

12 Apetrei C, Robertson DL, Marx PA. The history of SIVs and AIDS: epidemiology, phylogeny, and biology of isolates from naturally SIV-infected non-human primates (NHP) in Africa. Front. Biosci. 9, 225-254 (2004).

13 Wolfe ND, Dunavan CP, Diamond J. Origins of major human infectious diseases. Nature 447(7142), 279-283 (2007).

14 Kalish ML, Wolfe ND, Ndongmo CB et al. Central African hunters exposed to simian immunodeficiency virus. Emerg. Infect. Dis. 11(12), 1928-1930 (2005).

- Demonstrates a high prevalence of antibodies against several SIVs in Central Africans exposed to bushmeat, and also a high correlation between exposure and prevalence $(17.1 \%$ in very exposed rurals, $7.8 \%$ in moderately exposed rurals and $2.3 \%$ in general population). No viral sequence could be retrieved. This shows that human simian immunodeficiency virus (SIV) 
Perspective Sousa, Müller \& Vandamme

infections are common and probably going on since millennia. Therefore, the fact that HIV emerged only in 20th century requires an explanation. Replicated in Djoko et al. [15].

15 Djoko CF, Wolfe ND, Aghokeng AF et al. Failure to detect simian immunodeficiency virus infection in a large Cameroonian cohort with high non-human primate exposure. EcoHealth 9(1), 17-23 (2012).

16 Wain LV, Bailes E, Bibollet-Ruche F et al. Adaptation of HIV-1 to its human host. Mol. Biol. Evol. 24(8), 1853-1860 (2007).

17 Sauter D, Schindler M, Specht A et al. Tetherin-driven adaptation of Vpu and Nef function and the evolution of pandemic and nonpandemic HIV-1 strains. Cell Host Microbe 6, 409-421 (2009).

18 Kluge SF, Mack K, Iyer SS et al. Nef proteins of epidemic HIV-1 Group O strains antagonize human tetherin. Cell Host Microbe 16, 639-650 (2014).

19 Apps R, Del Prete GQ, Chatterjee P et al. HIV-1 Vpu mediates HLA-C downregulation. Cell Host Microbe 19, 686-695 (2016).

20 Van Dooren S, Salemi M, Vandamme A-M. Dating the origin of the African human T-cell lymphotropic virus type-I (HTLV-I) subtypes. Mol. Biol. Evol. 18(4), 661-671 (2001).

-. The tMRCAs of several HTLV-1 strains epidemic in humans (subtypes 1a and 1b) were calculated in this study, and they turned out to be between $12,300( \pm 4900)$ and $7800( \pm 2500)$ years ago, respectively. This shows that, unlike SIV, STLV-1 was able to cross to humans and emerge epidemically millenia ago.

21 Salemi M, Desmyter J, Vandamme A-M. Tempo and mode of human and simian T-lymphotropic virus (HTLV/STLV) evolution revealed by analyses of full-genome sequences. Mol. Biol. Evol. 17(3), 374-386 (2000).

-. Demonstrates that HTLV-2 split from STLV-2 (today found in Pan paniscus) occurred about 400,000 years ago. The tMRCA of human strains found in Amerindians is 22,000 (12,000-38,000) years ago, and the split between Amerindian and African strains dates back to the human out of Africa expansion. Again, this shows that STLV-2, like STLV-1, and unlike SIV, was able to cross to humans and emerge epidemically millenia ago.

22 Salemi M, Van Dooren S, Vandamme A-M. Origin and evolution of human and simian T-cell lymphotropic viruses. AIDS Rev. 1(3), 131-139 (1999).

23 Betsem E, Rua R, Tortevoye P, Froment A, Gessain A. Frequent and recent human acquisition of simian foamy viruses through apes' bites in Central Africa. PLoS Pathog. 7(10), e1002306 (2011).

24 Salemi M, Strimmer K, Hall WW et al. Dating the common ancestor of SIVcpz and HIV-1 group M and the origin of HIV-1 subtypes using a new method to uncover clock-like molecular evolution. FASEB J. Print 15, 276-278 (2001).

25 Korber B, Muldoon M, Theiler J et al. Timing the ancestor of the HIV-1 pandemic strains. Science 288(5472), 1789-1796 (2000).

26 Worobey M, Gemmel M, Teuwen DE et al. Direct evidence of extensive diversity of HIV-1 in Kinshasa by 1960. Nature 455(7213), 661-665 (2008).

27 Faria NR, Rambaut A, Suchard MA et al. The early spread and epidemic ignition of HIV-1 in human populations. Science 346(6205), 56-61 (2014).

- Convincingly showed, using phylogeographic and phylodynamic analyses, that Kinshasa was indeed the early epicenter of HIV-1-M. It also provided a new calculation of HIV-1-M tMRCA at 1920 (1909-1916) and showed that HIV-1-M subtype C, probably resulted from a founder effect taking place in the late 1930s, in the Katanga 'copper belt' region (southern Congo).

28 Lemey P, Pybus OG, Rambaut A et al. The molecular population genetics of HIV-1 group O. Genetics 167(3), 1059-1068 (2004).

29 Faria NR, Hodges-Mameletzis I, Silva JC et al. Phylogeographical footprint of colonial history in the global dispersal of human immunodeficiency virus type 2 group A. J. Gen. Virol. 93(Pt 4), 889-899 (2012).

30 Lemey P, Pybus OG, Wang B, Saksena NK, Salemi M, Vandamme A-M. Tracing the origin and history of the HIV-2 epidemic. Proc. Natl Acad. Sci. USA 100(11), 6588-6592 (2003).

31 Wertheim JO, Worobey M. Dating the age of the SIV lineages that gave rise to HIV-1 and HIV-2. PLoS Comput. Biol. 5(5), e1000377 (2009).

32 Worobey M, Telfer P, Souquière S et al. Island biogeography reveals the deep history of SIV. Science 329(5998), 1487 (2010).

-• Recalibrated the whole SIV phylogenetic tree to take into account the separation between the Bioko island and the African mainland, which happened about 10,000 years ago and left some SIVs evolving separately in the islander monkeys. This adds to the argument that opportunities for humans to acquire SIV are old.

33 Hooper E. The River: A Journey to the Source of HIV and AIDS. Little, Brown and Company, London, UK (2000).

34 Chitnis A, Rawls D, Moore J. Origin of HIV-1 in colonial French Equatorial Africa? AIDS Res. Hum. Retroviruses 16(1), 5-8 (2000).

35 Marx PA, Alcabes PG, Drucker E. Serial human passage of simian immunodeficiency virus by unsterile injections and the emergence of epidemic human immunodeficiency virus in Africa. Philos. Trans. R. Soc. Lond. B Biol. Sci. 356(1410), 911-920 (2001).

- The principle of adaptation of a virus to a new host species by serial passage is neatly enunciated. The authors review evidence of this process operating in experimental cross-species transfers of SIV and provide a mutational model. See also Herfst et al. [59] for a similar demonstration with $\mathrm{H} 5 \mathrm{~N} 1$ among ferrets. 
36 Gisselquist D. Emergence of HIV type 1 epidemic in the twentieth century: comparing hypotheses to evidence. AIDS Res. Hum. Retroviruses 19(12), 1071-1078 (2003).

37 Pépin J, Labbé A-C. Noble goals, unforeseen consequences: control of tropical diseases in colonial Central Africa and the iatrogenic transmission of blood-borne viruses. Trop. Med. Int. Health 13(6), 1-10 (2008).

38 Pépin J. The Origins of AIDS. Cambridge University Press, Cambridge, UK (2011).

39 Schneider WH, Drucker E. Blood transfusions in the early years of AIDS in sub-Saharan Africa. Am. J. Public Health 96(6), 984-994 (2006).

40 Sousa JD, Müller V, Lemey P, Vandamme A-M. High GUD incidence in the early 20th century created a particularly permissive time window for the origin and initial spread of epidemic HIV strains. PLoS ONE 5(4), e9936 (2010).

-. In this article, the debate about the possible importance of genital ulcer disease (GUD) and enhanced heterosexual transmission to understand the origin of HIV was inaugurated. GUD incidence over time in several African colonial cities, with an emphasis on Kinshasa was reviewed. Evidence shows that GUD was a novel factor in colonial equatorial Africa. Computer simulations were used to test the plausibility of an ill-adapted HIV capable only of acute infection to spread initially and adapt. The simulations showed that this initial spread was far more probable with the high GUD levels of early 20th century than with the low GUD levels of mid 20th century. In a no-GUD rural scenario, spread was not possible.

41 Sousa JD, Alvarez C, Vandamme A-M, Müller V. Enhanced heterosexual transmission hypothesis for the origin of pandemic HIV-1. Viruses 4(10), 1950-1983 (2012).

42 Giles-Vernick T, Gondola D, Lachenal G, Schneider WH. Social history, biology, and the emergence of HIV in colonial Africa. J. Afr. Hist. 54(1), 11-30 (2013).

- Anthropological critique to both our hypotheses (which we address in the present article) and to other hypotheses. More generally, the authors emphasize the need of using multidisciplinary research, including anthropology and colonial history, in this field. As they note, prostitution in colonial Leopoldville was behaviorally different than that seen in modern African cities.

43 Sousa JD, Temudo MP, Hewlett BS, Camacho RJ, Müller VM, Vandamme A-M. Male circumcision and the epidemic emergence of HIV-2 in West Africa. PLoS ONE 11(12), e0166805 (2016).

44 Schmid GP, Buvé A, Mugyenyi $\mathrm{P}$ et al. Transmission of HIV infection in sub-Saharan Africa and effect of elimination of unsafe injections. Lancet 363(9407), 482-488 (2004).

45 White RG, Cooper BS, Kedhar A et al. Quantifying HIV-1 transmission due to contaminated injections. Proc. Natl Acad. Sci. USA 104(23), 9794-9799 (2007).

46 Hahn BH, Shaw GM, De Cock KM, Sharp PM. AIDS as a zoonosis: scientific and public health implications. Science 287(5453), 607-614 (2000).

47 Demma LJ, Logsdon JM, Jr, Vanderford TH, Feinberg MB, Staprans SI. SIVsm quasispecies adaptation to a new simian host. PLoS Pathog. 1(1), e3 (2005).

48 Novembre FJ, Saucier M, Anderson DC et al. Development of AIDS in a chimpanzee infected with human immunodeficiency virus type 1. J. Virol. 71(5), 4086-4091 (1997).

49 Novembre FJ, Rosayro J, Nidtha $\mathrm{S}$ et al. Rapid CD4 ${ }^{+}$T-cell loss induced by human immunodeficiency virus type $1_{\mathrm{NC}}$ in uninfected and previously infected chimpanzees. J. Virol. 75(11), 1533-1539 (2001).

50 Wasserheit JN. Epidemiological synergy: interrelationships between human immunodeficiency virus infection and other sexually transmitted diseases. Sex. Transm. Dis. 19(2), 61-77 (1992).

51 Cohen MS. Amplified transmission of HIV-1: missing link in the HIV pandemic. Trans. Am. Clin. Climatol. Assoc. 117, 213-225 (2006).

52 Lawn SD. AIDS in Africa: the impact of coinfections on the pathogenesis of HIV-1 infection. J. Infect. 48, 1-12 (2004).

53 Cameron DW, Simonsen JN, D'Costa LJ et al. Female to male transmission of human immunodeficiency virus type 1: risk factors for seroconversion in men. Lancet 2(8660), 403-407 (1989).

54 Hayes RJ, Schulz KF, Plummer FA. The cofactor effect of genital ulcers on the per-exposure risk of HIV transmission in sub-Saharan Africa. J. Trop. Med. Hyg. 98(1), 1-8 (1995).

55 Apetrei C, Lerche NH, Pandrea I et al. Kuru experiments triggered the emergence of pathogenic SIV $_{\text {mac. }}$ AIDS 20(3), 317-321 (2006).

56 Coquery-Vidrovitch C. Le Congo au Temps des Grandes Compagnies Concessionnaires, 1898-1930. Mouton, Paris, France (1972).

57 Harms RW. River of Wealth, River of Sorrow: The Central Zaire Basin in the Era of the Slave and Ivory Trade, 1500-1891. Yale University Press, New Haven, USA (1981).

58 Vansina J. Paths in the Rainforests: Toward a History of Political Tradition in Equatorial Africa. The University of Wisconsin Press, Madison, USA (1990).

59 Herfst S, Schrauwen EJA, Linster M et al. Airborne transmission of influenza A/H5N1 virus between ferrets. Science 336(6088), 1534-1541 (2012).

60 Gisselquist DP, Upham G, Potterat JJ. Efficiency of human immunodeficiency virus transmission through injections and other medical procedures: evidence, estimates, and unfinished business. Infect. Control Hosp. Epidemiol. 27(9), 944-952 (2006). 
61 Croix Rouge du Congo. Rapport Annuel [1928 through 1954]. Croix Rouge de Belgique, Brussels, Belgium (1928-1954).

62 Vamos S. Traitement de trypanosomés dans un secteur du Moyen-Chari (A.E.F.): étude de 3705 observations. B. Soc. Pathol. Exot. 29(9), 1015-1022 (1936).

63 Njouom R, Nerrienet E, Dubois $\mathrm{M}$ et al. The hepatitis $\mathrm{C}$ virus epidemic in Cameroon: genetic evidence for rapid transmission between 1920 and 1960. Infect. Genet. Evol. 7(3), 361-367 (2007).

64 Frank C, Mohamed MK, Strickland GT et al. The role of parenteral antischistosomal therapy in the spread of hepatitis C virus in Egypt. Lancet 355(9207), 887-891 (2000).

65 Pépin J, Chakra CNA, Pépin E, Nault V. Evolution of the global use of unsafe medical injections, 2000-2010. PLoS ONE 8(12), e80948 (2013).

66 Van den Branden F, Van Hoof L. Rapport sur le fonctionnement du Laboratoire de Léopoldville pendant l'année 1922. Ann. Soc. Belg. Med. Trop. 3, 157-180 (1923).

67 Martin G, Leboeuf A, Rigenbach G. Thérapeutique et prophylaxie chimiques de la maladie du sommeil. Ann. Hyg. Med. Colon. 13, 99-129 (1910).

68 Royaume de Belgique. Colonie du Congo Belge. Rapport sur L'hygiène Publique Pendant L'année [1925 through 1929]. F van Gompel, Brussels, Belgium (1925-1929).

69 Jamot E. Essai de Prophylaxie médicale de la Maladie du Sommeil dans l'Oubangui-Chari. B. Soc. Pathol. Exot. 13(5), 343-376 (1920).

70 Jamot E. La Maladie du Sommeil au Cameroun en Janvier 1929. B. Soc. Pathol. Exot. 22(6), 473-496 (1929).

71 Hogan CA, Iles J, Frost EH et al. Epidemic history and iatrogenic transmission of blood-borne viruses in mid-20th century Kinshasa. J. Infect. Dis. 214(3), 353-360 (2016).

72 Abdala N, Gleghorn AA, Carney JM, Heimer R. Can HIV-1-contaminated syringes be disinfected? Implications for transmission among injection drug users. J. Acquir. Immune Defic. Syndr. 28(5), 487-494 (2001).

73 Baggaley RF, Boily M-C, White RG, Alary M. Risk of HIV-1 transmission for parenteral exposure and blood transfusion: a systematic review and meta-analysis. AIDS 20(6), 805-812 (2006).

74 Colin ML. Mode de préparation des solutions d'arsénobenzol, billon, de salvarsan, et de néosalvarsan à l'hôpital de Saigon et leur introduction par voie veineuse dans l'organisme. Ann. Hyg. Med. Colon. 17, 284-292 (1914).

75 Kubitschke A, Bader C, Tillmann HL, Manns MP, Kuhn S, Wedemeyer H. Verletzungen MIT hepatitis-C-virus kontaminierten Nadeln: Wie hoch ist das Risiko einer Serokonversion bei medizinischen Personal wirklich. Internist (Berlin) 48(10), 1165-1172 (2007).

76 Centers for Disease Control and Prevention. Hepatitis C FAQs for health professionals (2017). www.cdc.gov/hepatitis/hcv/hcvfaq.htm

77 Harding RD. A Yaws campaign in Sierra Leone. T. R. Soc. Trop. Med. H. 42(4), 347-366 (1949).

78 Carlson JM, Schaefer M, Monaco DC et al. Selection bias at the heterosexual HIV-1 transmission bottleneck. Science 345(6193), 1254031 (2014).

79 Korenromp EL, Bakker R, de Vlas SJ et al. HIV dynamics and behaviour change as determinants of the impact of sexually transmitted disease treatment on HIV transmission in the context of the Rakai trial. AIDS 16, 2209-2218 (2002).

80 Weiler AM, Li Q, Duan L et al. Genital ulcers facilitate rapid viral entry and dissemination following intravaginal inoculation with cell-associated simian immunodeficiency virus SIVmac239. J. Virol. 82(8), 4154-4158 (2008).

81 Pépin J. The expansion of HIV-1 in colonial Leopoldville, 1950s: driven by STDs or STD control? Sex. Transm. Infect. 88(4), 307-312 (2012).

82 Boily M-C, Baggaley RF, Wang L et al. Heterosexual risk of HIV-1 infection per sexual act: systematic review and meta-analysis of observational studies. Lancet Infect. Dis. 9(2), 118-129 (2009).

83 Powers KA, Poole C, Pettifor AE, Cohen MS. Rethinking the heterosexual infectivity of HIV-1: a systematic review and meta-analysis. Lancet Infect. Dis. 8(9), 553-563 (2008).

84 Kreiss JK, Koech D, Plummer FA et al. (1986) AIDS virus infection in Nairobi prostitutes. Spread of the epidemic to East Africa. $N$. Engl. J. Med. 314(7), 414-418 (1986).

85 Cabral A. Histórias do Zaire. Livros Horizonte, Lisbon, Portugal (1947).

86 Moyer D, Plumptre AJ, Pintea L et al. Surveys of Chimpanzees and other Biodiversity in Western Tanzania. Wildlife Conservation Society and The Jane Goodall Institute, VA, USA (2006).

87 Lee S. Cercocebus atys. Animal Diversity Web, University of Michigan, MI, USA (2012). http://animaldiversity.org/accounts/Cercocebus_atys/

88 Clifford SL, Anthony NM, Bawe-Johnson M et al. Mitochondrial DNA phylogeography of western lowland gorillas (Gorilla gorilla gorilla) Mol. Ecol. 13(6), 1551-1565 (2004).

89 Weiss H. Epidemiology of herpes simplex virus type 2 infection in the developing world. Herpes 11(Suppl. 1), A24-A35 (2004).

90 Mbopi-Kéou FX, Grésenguet G, Mayaud P et al. Interactions between herpes simplex virus type 2 and human immunodeficiency virus type 1 infection in African women: opportunities for intervention. J. Infect. Dis. 182(4), 1090-1096 (2000). 
91 Mbopi-Keou FX, Robinson NJ, Mayaud P, Belec L, Brown DW. Herpes simplex virus type 2 and heterosexual spread of human immunodeficiency virus infection in developing countries: hypotheses and research priorities. Clin. Microbiol. Infect. 9(3), 161-171 (2003).

92 Nahmias AJ, Lee FK, Beckam-Nahmias S. Sero-epidemiological and -sociological patterns of herpes simplex virus infection in the world. Scand. J. Infect. Dis. 22(Suppl. 69), 19-36 (1990).

93 Headrick R. Colonialism, Health and Illness in French Equatorial Africa, 1885-1935. African Studies Associated Press, GA, USA (1994).

94 Mouchet R. Yaws and syphilis among natives of the Belgian Congo. Kenya Med. J. 3(9), 242-245 (1926).

95 Kermorgant A. Aperçu sur les maladies vénériennes dans les colonies Françaises. Ann. Hyg. Med. Colon. 6, 428-460 (1903).

96 Spire D. Rapport médicale de la mission Fourneau. Ann. Hyg. Med. Colon. 5, 353-379 (1902).

97 Retel-Laurentin A. Un Pays à la Dérive: une Societé en Régression Démographique: les Nzakara de l'Est Centrafricain. Jean-Pierre Delarge, Paris, France (1979).

98 Hurault J. Fecondité et mortalité dans l'agglomération urbaine de Banyo (Cameroun): l'incidence des maladies vénériennes. Cahiers de l'ORSTOM, Séries Sciences Humaines 21, 247-267 (1983).

99 Oxman GL, Smolkowski K, Noell J. (1996) Mathematical modeling of epidemic syphilis transmission. Implications for syphilis control programs. Sex. Transm. Dis. 23(1), 30-39 (1996).

100 Sousa JD, Vandamme A-M, Müller V. Syphilis and chancroid as novel factors potentially driving HIV emergence. Presented at: Symposium: From emerging to pandemic viruses, Conférences Jacques Monod. Roscoff, France, 2-6 April 2014.

101 Steen R. Eradicating chancroid. Bull. World Health Organ. 79(9), 818-826 (2001).

102 Trezenem E. Notes ethnographiques sur les tribus Fan du Moyen-Ogooué. J. Soc. Africanistes 6, 65-93 (1936).

103 Schwab C. Tribes of the Liberian Hinterland: Report of the Peabody Museum Expedition to Liberia. Peabody Museum of American Archaeology and Ethnology, Cambridge, MA, USA (1947).

104 Baumann H, Westermann D. Les Peuples et les Civilizations de l'Afrique. Payot, Paris, France (1962).

105 Armelagos GJ, Zuckerman MK, Harper KN. The science behind pre-Columbian evidence of syphilis in Europe: research by documentary. Evol. Anthropol. 21(2), 50-57 (2012).

106 Gangaiah D, Webb KM, Humphreys TM et al. Haemophilus ducreyi cutaneous ulcer strains are nearly identical to class i genital ulcer strains. PLoS Negl. Trop. Dis. 9(7), e0003918 (2015).

107 Pineda-Peña A, Varanda J, Sousa JD et al. On the contribution of Angola to the initial spread of HIV-1. Infect. Genet. Evol. 46, 219-222 (2016).

108 Merfield FG. Gorillas Were My Neighbours. The Company Book Club, London, UK (1957).

109 Koch CWH. Die stämme des bezirks molundu: in sprachlicher, geschichtlicher und völkerkundlicher beziehung. Bässler-Archiv: Beiträge zu Völkerkunde 3, 257-312 (1913).

110 Bongaarts J, Reining P, Way P, Conant F. The relationship between male circumcision and HIV infection in African populations. AIDS 3(6), 373-377 (1989).

111 Shaw GM, Hunter E. HIV transmission. Cold Spring Harb. Perspect. Med. 2, a006965 (2012).

112 Haaland RE, Hawkins PA, Salazar-Gonzalez J et al. Inflammatory genital infections mitigate a severe genetic bottleneck in heterosexual transmission of subtype A and C HIV-1. PLoS Pathog. 5(1), e1000274 (2009).

113 Yamaguchi J, Coffey R, Vallari A et al. Identification of HIV type 1 group $\mathrm{N}$ infections in a husband and wife in Cameroon: viral genome sequences provide evidence for horizontal transmission. AIDS Res. Hum. Retroviruses 22(1), 83-92 (2006).

114 Orroth KK, Freeman EE, Bakker R et al. Understanding the differences between contrasting HIV epidemics in east and west Africa: results from a simulation model of the Four Cities Study. Sex. Transm. Infect. 83(Suppl. I), i5-i16 (2007).

115 Brown RC, Brown JE, Ayowa OB. The use and physical effects of intravaginal substances in Zairian women. Sex. Transm. Dis. 20(2), 96-99 (1993).

116 Kun KE. Vaginal drying agents and HIV transmission. Int. Fam. Plan. Perspec. 24(2), 93-94 (1998).

117 Wald A, Zeh J, Selke S et al. Reactivation of genital herpes simplex virus type 2 infection in asymptomatic seropositive persons. N. Engl. J. Med. 342, 844-850 (2000).

118 Ferdinandy B, Mones E, Vicsek T, Müller V. HIV competition dynamics over sexual networks: first comer advantage conserves founder effects. PLoS Comput. Biol. 11(2), e1004093 (2015). 
(

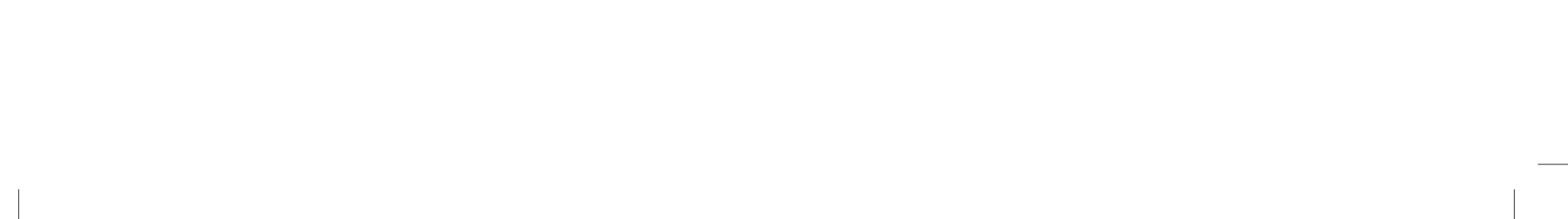

